\title{
RC BEAMS STRENGTHENED WITH HPFRCC: EXPERIMENTAL AND NUMERICAL RESULTS
}

\author{
Mykolas DAUGEVIČIUS, Juozas VALIVONIS, Tomas SKUTURNA, Vladimir POPOV \\ Department of Concrete and Masonry Structures, Faculty of Civil Engineering, \\ Vilnius Gediminas Technical University, Sauletekio al. 11, Vilnius, Lithuania
}

Received 18 May 2015; accepted 21 Oct 2015

\begin{abstract}
The study analyses the behaviour of reinforced concrete beams strengthened with high-performance fibrereinforced cementitious composite (HPFRCC). Six beams were divided into two equal groups and strengthened. In total, nine beams were tested, including three control beams that were not strengthened. Control beams were over-reinforced. The beams of the first group were strengthened in the compressed part while those of the second group were strengthened in the compressed and tensioned parts of the section. The experimental results of all tested beams were compared with numerical results. The positive and negative effects of strengthening the resistance and serviceability of the beams were experimentally determined. The obtained results showed that the load-carrying capacity of all strengthened beams increased and their deflections decreased; however, crack width in the beams of the second group increased while that of the beams of the first group decreased. The width of cracks increased because the number of cracks decreased. The findings of this study show a comparison of strains, deflections, cracking and load-carrying capacity and indicate that strengthening changed the failure of the beams.
\end{abstract}

Keywords: HPFRCC, strengthening, deformability, cracking, neutral axis, deflection.

\section{Introduction}

Several factors can increase the deformability of reinforced concrete beams. Among them is an increased external load, the damaged composition of concrete and decreased bending stiffness. These and other factors associated with an increase in deformability usually increase the evolution of plastic deformations. Strengthening by the restoration of the damaged concrete layer or by the installation of a new layer can be done in order to decrease the evolution of plastic deformations. Ordinary high-strength concrete can be used for retrofitting RC beams, but ultimate deformations of this type of concrete are usually smaller than those of ordinary-strength concrete (Cai, Xu 2011). High-performance or ultra-highperformance fibre-reinforced cementitious composite (HPFRCC or UHPFRCC) can be used in order to increase the ductility of the beam. As suggested by other researchers (Brühwiler, Denarié 2013; Farhat et al. 2007; Kobayashi, Rokugo 2013; Nan, Shi-lang 2011), HPFRCC or UHPFRCC are perfect materials for strengthening RC structures and are different from ordinary concrete as they have higher strength, a higher modulus of elasticity, higher ultimate deformation and different tensile strength. Due to high compressive strength and a higher modulus of elasticity, the compressed part of the cross-section of the beams can be strengthened. Thus, the evolution of plastic deformations can be reduced. Further, due to different tensile strength, the tensioned part of the crosssection can be strengthened.

Cracking strength and post-cracking strength can be differentiated for HPFRCC and UHPFRCC materials (Kim et al. 2012). After crack opening, stresses transfer onto fibres, and tensile strength slightly increases. Therefore, fibres exert tension-strain hardening effect, which in turn creates the deflection-hardening effect (Naaman, Reinhardt 2006). Therefore, bending stiffness should increase. The performed experiments have determined that strain-hardening effect is influenced by fibre and concrete bond strength (Yoo et al. 2013). Then, the pull-out of fibres is initiated and followed by stress-strain softening effect (Yoo et al. 2013).

The optimal composition of the HPFRCC or UHPFRCC mixture should be used because the number of fibres and their length also influence bending stiffness. A growth in the amount of fibre increases strain hardening and post-cracking strength (Wille et al. 2012). Again, this can increase bending stiffness due to the increased deflection-hardening effect. However, the carried out experiments have determined that compressive strength can decrease due to the heterogeneous distribution of

Corresponding author: Mykolas Daugevičius

E-mail: mykolas.daugevicius@vgtu.lt 
fibres (Yoo et al. 2013). Therefore, excessive fibres can decrease bending stiffness. A change in the temperature of fibres can also decrease compressive strength (Farhat et al. 2007). The length of fibres also negatively and positively influences bending stiffness. The experiments have determined that long fibres ensure better fracture energy, whereas short fibres ensure better compressive and tensile strength (Karihaloo 2012). The contribution of fibres changes the failure of a brittle material in the ductile one and can also increase Poisson's ratio (Cai, Xu 2011).

The carbon fibre reinforced polymer (CFRP) composite material is also used for strengthening bent reinforced concrete elements. Experimental researches (Marčiukaitis et al. 2007; Skuturna et al. 2008; Daugevičius et al. 2012; Skuturna, Valivonis 2014, 2015) show that flexural stiffness increases due to the increased depth of the neutral axis. However, thin CFRP plates do not change the crosssection of the strengthened element. Strengthening with HPFRCC material changes the cross-section and bending stiffness increases due to the increased cross-section.

A literature review shows that extensive experimental investigations on $\mathrm{RC}$ beams strengthened with the high-strength fibre-reinforced concrete material have been carried out (Ćirović et al. 2014; Farhat et al. 2007; Kobayashi, Rokugo 2013; Nan, Shi-lang 2011; KrstulovicOpara et al. 1997; Haddad et al. 2008; Habel et al. 2007; Martinola et al. 2010; Noshiravani, Brühwiler 2010; Kim et al. 2014; Hussein et al. 2012; Zhang et al. 2012; Ferrari et al. 2013; Li, Xu 2009; Elsanadedy et al. 2013; Zofka et al. 2014). Mechanical parameters for strengthening materials, including compressive strength, tensile strength and the modulus of elasticity were different in all these studies. Parameters for fibres also varied. Therefore, in all cases, the effect of strengthening was different. All studies have shown that bending stiffness, the cracking moment and load-carrying capacity were increased and that the distribution of cracks and the mode of the failure were also changed.

The aim of this research was to investigate the behaviour of the beams that were strengthened in the compressed part or in both the compressed and tensioned parts of the section. This conducted research differs from the others in that case that the beams were strengthened with HPFRCC, and the mixture of this material was freely available commercially. In fact, the REFOR-tec $\mathbb{R}$ GF5 mixture was used. The employment of this mixture helps with obtaining constant mechanical parameters for strengthening material.

\section{Characteristics of the beams}

Experimental reinforced concrete beams were over-reinforced, which allowed strengthening the compressed part of the section. In practice, the composition of concrete in the existing $\mathrm{RC}$ beams can be damaged due to harmful environmental conditions. The area of the concrete cross section can decrease, and therefore, the reinforcement ratio can change. Strengthening of experimental beams was carried out by increasing the width of the cross-section of the beam. Concreting a new layer of the HPFRCC material allowed an increase in the width of the cross-section. The strengthened beams were divided into two groups. The beams of the first group were strengthened in the compressed part of the section (Table 1) and named S1T, S2T and S3T. The beams of the second group were strengthened in both the compressed and tensioned parts of the section (Table 1) and named S4U, S5U and S6U. Control beams were named S7, S8 and S9. The reinforcement ratio of these beams reached $\mu=1.79 \%$. Such a high level of reinforcement increases the depth of the neutral axis; therefore, higher concrete compressive stresses are reached, and these beams can fail before reaching the yielding strength of the tensioned reinforcement. Strengthening the compressed part of the cross-section may help with exploiting the tensile strength of reinforcement, especially when high strength concrete is used for strengthening. The reinforcement ratio of SxT beams after strengthening changed to $\mu=1.39 \%$ while the reinforcement ratio of SxU beams changed to $\mu=1.28 \%$.

Concreting a new layer was accomplished only in the part of the beams between supports (Figs 1a and 1b). The type of strengthening similar to that in the SxT beam was possible only when floor slabs were removed from the carcass beams of the main structure or if floor hollow slabs were strengthened. Then, the analysed section of the strengthened hollow slab corresponds to this section (Fig. 1a). The type of strengthening similar to $\mathrm{SxU}$

Table 1. Characteristics of the beams

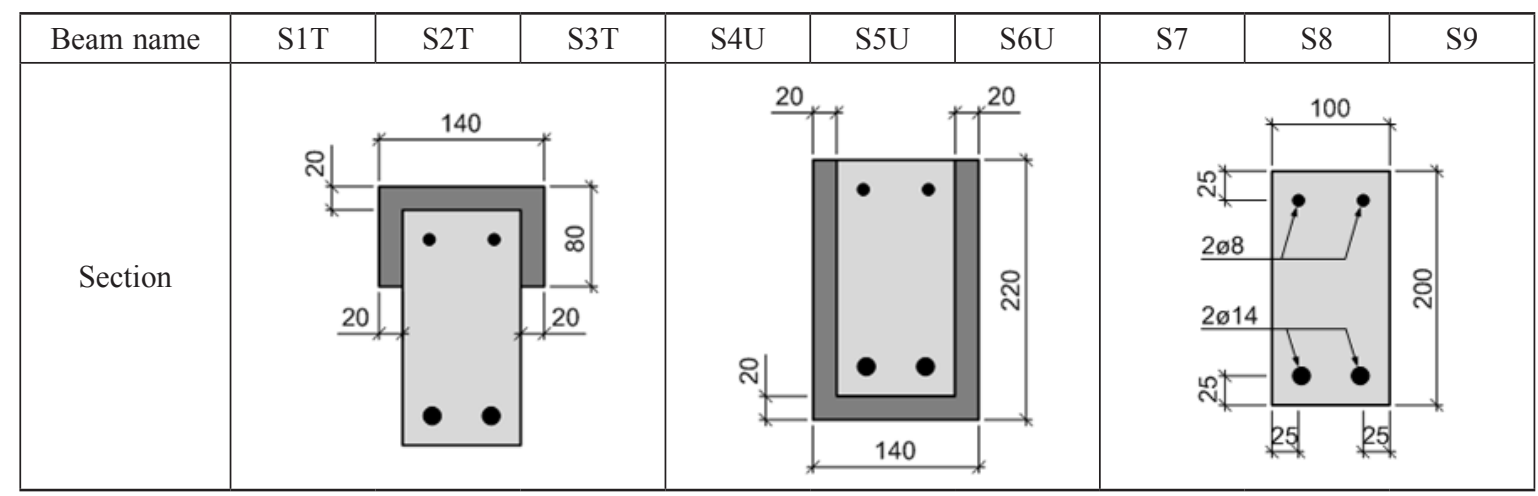


a)
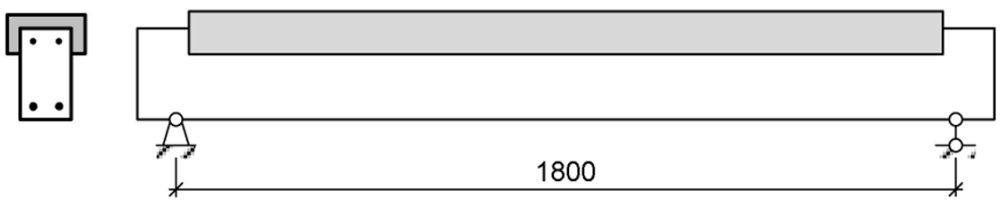

b)
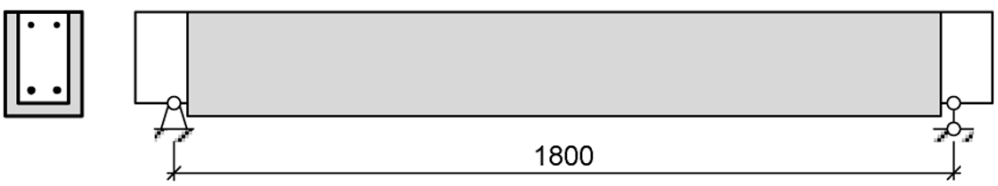

c)

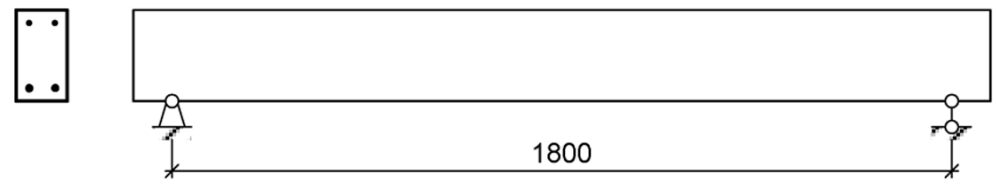

Fig. 1. Experimental beams: (a) SxT beams, (b) SxU beams, (c) Sx control beams

beams is possible only when holes are made in the floor slabs to pour the HPFRCC mixture. Strengthening with HPFRCC can increase the flexural resistance and stiffness of the beams. Further, resistance to shear force should be increased.

Strengthening was carried out in accordance with certain technological requirements. After concreting additional layers is completed, the newly formed cross-section must be monolithic. However, after strengthening, the cross-section can be divided into separate layers, particularly if the layers have a poor bond. Shear stresses increase between the layers thus leading to the displacement of the layers, whereby the cross-section cannot be considered as one piece (monolithic). This has a negative influence on its strength and deflection. Experimental research (Santos et al. 2007) has shown that the roughness of the surface increased bond strength up to two times as shear increased about $32 \%$.

In order to form a monolithic cross-section, cement particles of the poured concrete mixture must bind with old concrete aggregates. To that end, the surface of the beam was processed by high-pressure washing. Such treatment of the surface allowed removing small aggregates from old concrete. Gross aggregates of old concrete were uncovered. The particles of hydrated cement stone were removed from the surface of gross aggregates. The surface of old concrete became very coarse. Before pouring the new concrete mixture, the surface of the treated concrete was moistened. It should be noted that surface treatment with steel brushes do not afford an effect as good as that achieved by treatment with a high-pressure water jet. The views of treated surfaces are presented in Figure 2.

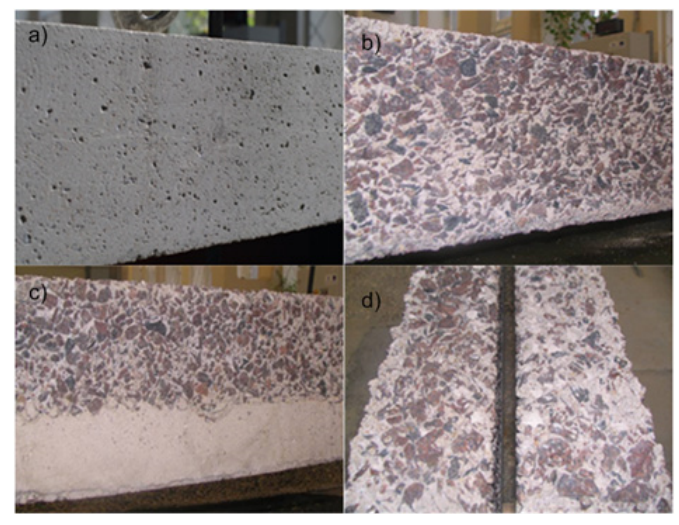

Fig. 2. Surfaces after treatment: (a) not suitable surface after treatment with steel brushes; (b) surface for beams SxU after treatment with high-pressure water jet; (c) and (d) surfaces of beams SxT

All beams were reinforced with the same carcass made from the same steel bars. A reinforcement scheme is presented in Figure 3. Ribbed steel bars were used for longitudinal and shear reinforcement. The latter one was used only in the parts where shear forces were exerted. At the middle part of the beam, shear reinforcement was not used because only major stresses acted in the pure bending zone.

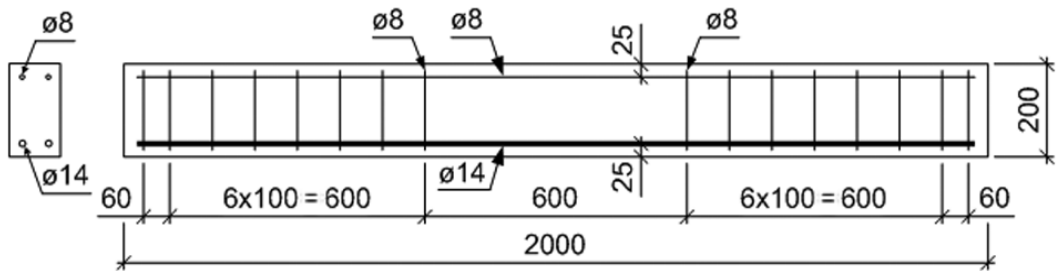

Fig. 3. Reinforcement schema 


\section{Characteristics of materials}

A different shape and size of concrete and HPFRCC material samples were tested in order to determine mechanical parameters (Fig. 4). This was because some calculation methods estimate the strength of the material from the samples of a different shape. For example, it is possi-

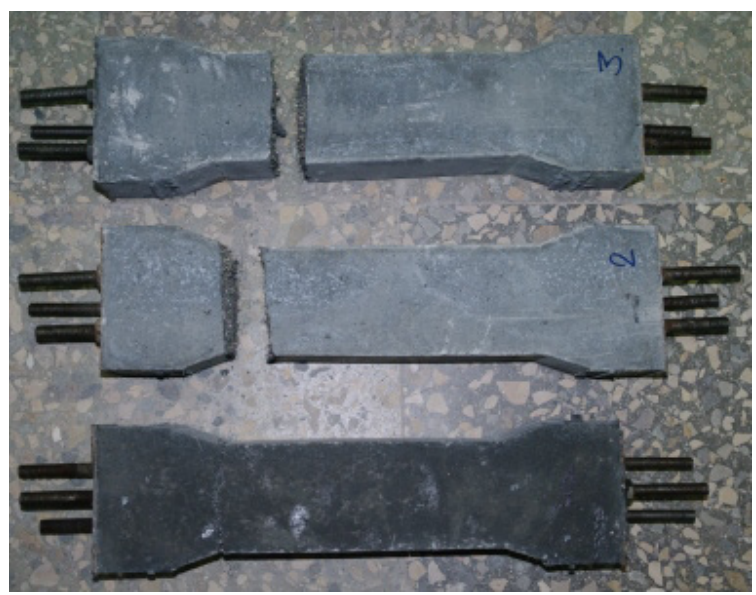

a)

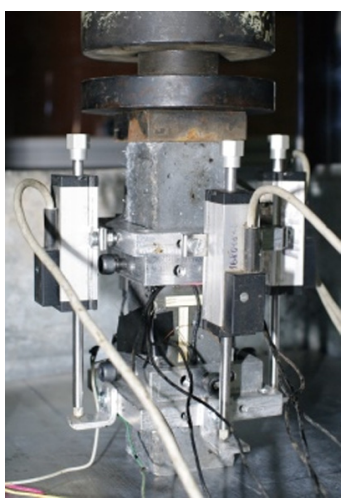

c)

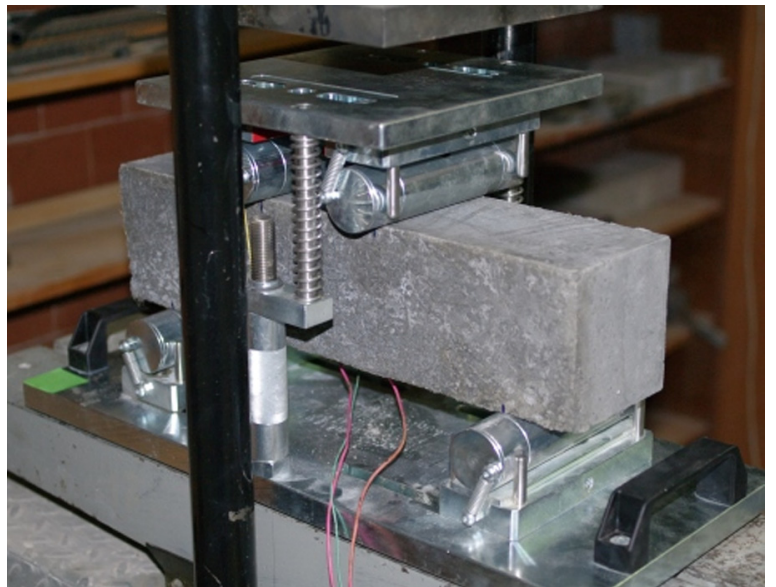

e) ble to calculate the load-carrying capacity of the beam by estimating compressive strength determined considering cylinders or prisms. Further, it is possible to determine the tensile strength of the material with reference to the flexural results of the test.

The tensile strength of concrete and HPFRCC materials was determined by testing samples, as shown in
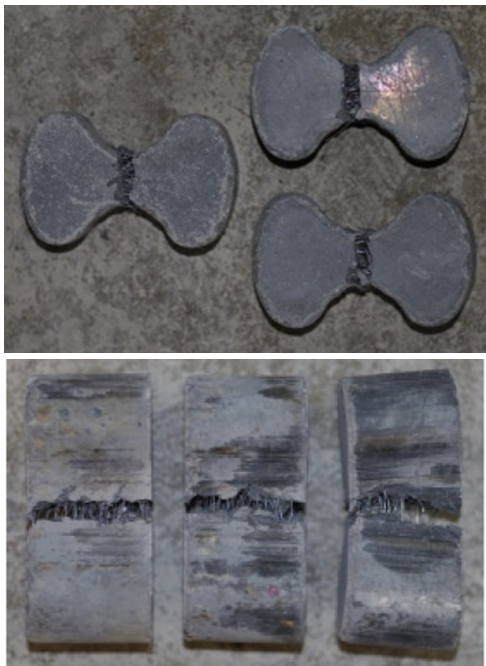

b)

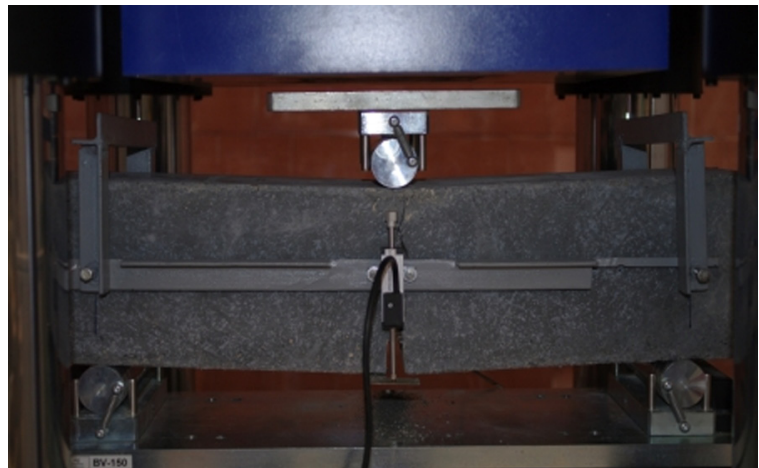

d)

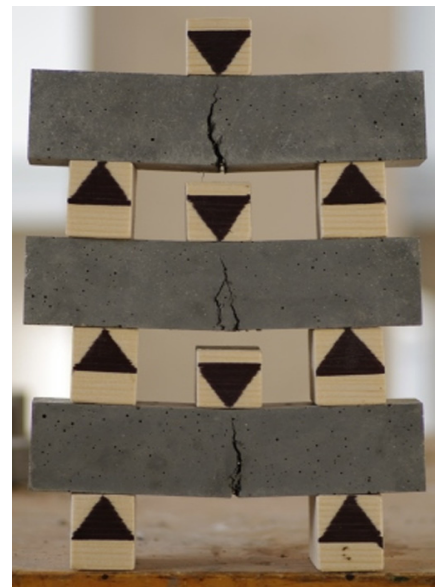

f)

Fig. 4. HPFRCC material samples of different shapes and sizes: (a) and (b) samples after tension, (c) testing of prisms $(40 \times 40 \times 160)$, (d) flexural test of prisms $(150 \times 150 \times 600)$, (e) - flexural test of prisms $(100 \times 100 \times 400)$, (f) - prisms $(40 \times 40 \times 160)$ after flexural test 
Figure 4a. The tensile strength of HPFRCC materials was also established in the course of testing samples, as indicated in Figure 4b. It was found that the tensile strength of HPFRCC depended on the sample size. The experimental tensile strength is presented in Table 2 .

Table 2. Tensile strength of concrete and HPFRCC

\begin{tabular}{l|c|c|c}
\hline \multicolumn{1}{c|}{ Sample } & Material & Strength, MPa & $f_{c c} / f_{c}$ \\
\hline \multirow{2}{*}{$\begin{array}{l}\text { Prism } 100 \times 100 \mathrm{~mm} \\
\text { (cross-section) }\end{array}$} & Concrete & 2.28 & 2.1 \\
\cline { 2 - 4 } & HPFRCC & 4.78 & - \\
\hline Dog bones & HPFRCC & 5.73 & - \\
\hline
\end{tabular}

The compressive strength of concrete and HPFRCC materials was determined by testing cylinders, cubes and prisms. Cubes and cylinders for compression were tested according to stipulations provided in EN 12390-3 (2009). Prisms for compression $(40 \times 40 \times 160 \mathrm{~mm})$ were tested according to stipulations provided in EN 13412 (2006). The experimental compressive strength is presented in Table 3. It was found that the compressive strength of HPFRCC did not depend on the size but on the form of the sample. The article also discusses statistical parameters such as standard deviation and the coefficient of variation (Daugevičius, Valivonis 2013).

Table 3. Strength of compressed samples

\begin{tabular}{c|l|c|c}
\hline Sample & Material & $\begin{array}{c}\text { Strength, } \\
\mathrm{MPa}\end{array}$ & $f_{c c} / f_{c}$ \\
\hline Cube $100 \times 100 \times 100 \mathrm{~mm}$ & HPFRCC & 111.5 & - \\
\hline \multirow{2}{*}{ Cube $150 \times 150 \times 150 \mathrm{~mm}$} & Concrete & 35.6 & \multirow{2}{*}{3.17} \\
\cline { 2 - 3 } & HPFRCC & 112.7 & \\
\hline \multirow{2}{*}{ Cylinder $150 \times 300 \mathrm{~mm}$} & Concrete & 32.4 & \multirow{2}{*}{3.48} \\
\cline { 2 - 3 } & HPFRCC & 112.9 & \\
\hline Prism $40 \times 40 \times 160 \mathrm{~mm}$ & HPFRCC & 105.4 & \multirow{2}{*}{3.93} \\
\hline \multirow{2}{*}{ Prism $100 \times 100 \times 400 \mathrm{~mm}$} & Concrete & 27.3 & \multirow{2}{*}{3.3} \\
\cline { 2 - 3 } & HPFRCC & 107.3 & \\
\hline
\end{tabular}

The experimental modulus of the elasticity of each material is presented in Table 4 . The modulus of elasticity is different not only because of different dimensions of the samples but also due to different loading rates used for the samples of a different size.

Table 4. Modulus of elasticity

\begin{tabular}{c|l|c|c}
\hline Sample & Material & $\begin{array}{c}\text { Modulus, } \\
\text { GPa }\end{array}$ & $E_{c c} / E_{c}$ \\
\hline \multirow{2}{*}{ Prism $100 \times 100 \times 400 \mathrm{~mm}$} & Concrete & 32.7 & \multirow{2}{*}{1.16} \\
\cline { 2 - 3 } & HPFRCC & 37.8 & \\
\hline \multirow{2}{*}{ Cylinder $150 \times 300 \mathrm{~mm}$} & Concrete & 29.9 & \multirow{2}{*}{1.15} \\
\cline { 2 - 3 } & HPFRCC & 34.5 & \\
\hline Prism $40 \times 40 \times 160 \mathrm{~mm}$ & HPFRCC & 42.48 & - \\
\hline
\end{tabular}

The flexural strength of concrete and HPFRCC material prisms $(100 \times 100 \times 400 \mathrm{~mm})$ was determined in accordance with EN 12390-5 (2009) and EN 14651 (2005) for prisms $150 \times 150 \times 600 \mathrm{~mm}$. The experimental flexural strength is presented in Table 5.

Table 5. Flexural strength

\begin{tabular}{c|c|c|c}
\hline \multicolumn{1}{c|}{ Sample } & Material & $\begin{array}{c}\text { Strength, } \\
\mathrm{MPa}\end{array}$ & $f_{c c} / f_{c}$ \\
\hline \multirow{2}{*}{ Prism $100 \times 100 \times 400 \mathrm{~mm}$} & Concrete & 3.57 & \multirow{2}{*}{4.45} \\
\cline { 2 - 3 } & HPFRCC & 15.9 & \\
\hline Prism $40 \times 40 \times 160 \mathrm{~mm}$ & HPFRCC & 10.84 & \\
\hline \multirow{2}{*}{ Prism $150 \times 150 \times 600 \mathrm{~mm}$} & Concrete & 3.59 & \multirow{2}{*}{3.86} \\
\cline { 2 - 3 } & HPFRCC & 13.86 & \\
\hline
\end{tabular}

The tensile properties of steel bars were determined in accordance with ISO 15630-1 (2002). The yielding strength of steel bars $\varnothing 14$ was $924 \mathrm{MPa}$ and that of the modulus of elasticity - $179 \mathrm{GPa}$. The yielding strength of steel bars $\varnothing 8$ was $609 \mathrm{MPa}$ and that of the modulus of elasticity - $199 \mathrm{GPa}$.

Axial and lateral deformations were measured during material testing. Stress-strain relations for compression and tension were determined (Figs 5a, 5b, 5c, and $5 \mathrm{~d})$. The ultimate deformation of compressed cylindrical samples is larger than that of prismatic samples. Further, the ultimate deformation of HPFRCC is also larger. However, the ultimate deformation of the prisms of a different size is almost similar. It can be concluded that when ordinary concrete in the compressed part of the beam crosssection reaches its maximum stresses, they will not be the highest ones in HPFRCC. Therefore, a proper stresses value in the HPFRCC layer should be taken into account, particularly that of SxU beams, according to the strain of ordinary concrete. Stress-strain curves (Fig. 5d) derived from a direct tension test show that deformation at the rupture of the HPFRCC sample is larger than that of concrete. Thus, during the flexural test, cracking should first start in ordinary concrete and then in the HPFRCC layer. Therefore, two cracking moments should be determined. Stress-strain curves (Figs $5 \mathrm{~d}$ and $5 \mathrm{e}$ ) and stressdeflection curves (Fig. 5f) show that the tensile strength of HPFRCC remains after a crack opening. The residual strength of HPFRCC must be evaluated, following which the load-carrying capacity of $\mathrm{SxU}$ beams is calculated.

\section{Experimental investigation}

The four-point bending test was carried out. The load was increased step-by-step. At each load step, cracks in the tensioned part of the cross-section were observed. For establishing the crack width, a microscope magnifying 24 times was used. Before cracks appeared, the load step reached $5 \mathrm{kN}$. The appearance of cracks was noted visually. After crack opening, the load step increased to $20 \mathrm{kN}$. An external load was transferred through steel plates on which mobile and immobile steel hinges were 

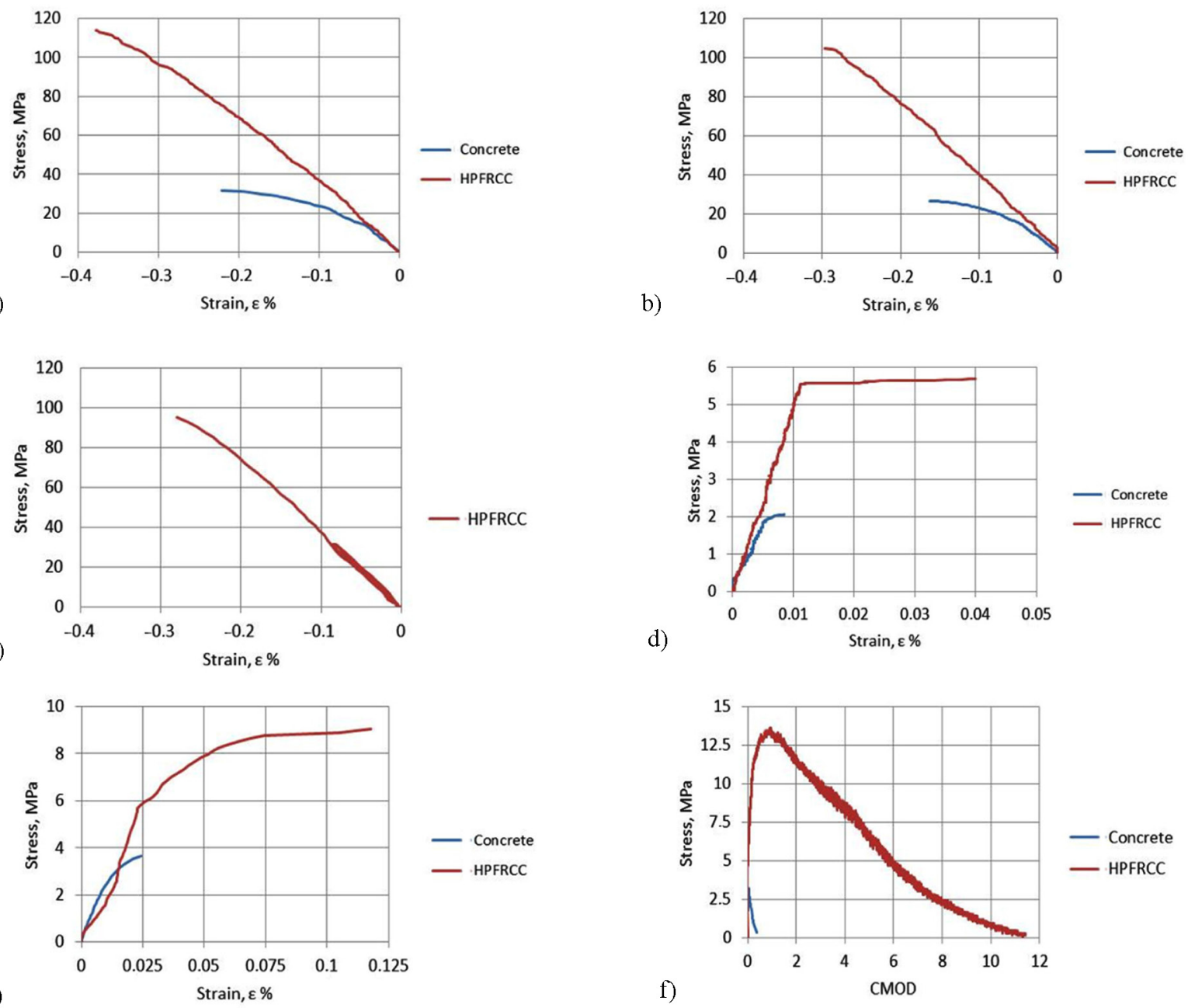

Fig. 5. Stress-strain and stress-deflection curves: (a) stress-strain curves of cylinder samples, (b) stress-strain curves of prismatic samples, (c) stress-strain curve of prismatic $(40 \times 40 \times 160)$ sample, (d) stress-strain curves of tensioned prismatic $(100 \times 100)$ samples, (e) stress-strain curves derived from flexural test of prismatic $(100 \times 100 \times 400)$ samples,

(f) stress-deflection curves of prismatic $(150 \times 150 \times 600)$ samples

attached. The length of steel plates was equal to the width of SxT and SxU beams. The scheme for beam testing is presented in Figure 6.

Deflections and deformations were measured at different locations. The respective locations of deformation measuring devices I1, I2, I3, I4 and I5 on the SxT beam were as follow: the top of the compressed HPFRCC layer, the top of the compressed concrete layer and the bottom of the HPFRCC layer, the compressed layer with the steel bar, the tensioned layer with the steel bar, the bottom of the tensioned concrete. The locations of deformationmeasuring devices I1, I2, I3, I4 and I5 on the SxU beam were the top of the compressed concrete layer, the compressed layer with the steel bar, the tensioned layer with the steel bar, the bottom of the tensioned concrete layer and the top of the HPFRCC layer and the bottom of the tensioned HPFRCC layer respectively. The location of deformation-measuring devices I1, I2, I3 and I4 on Sx beams were the top of the compressed concrete layer, the compressed layer with the steel bar, the tensioned layer with the steel bar and the bottom of the tensioned con-
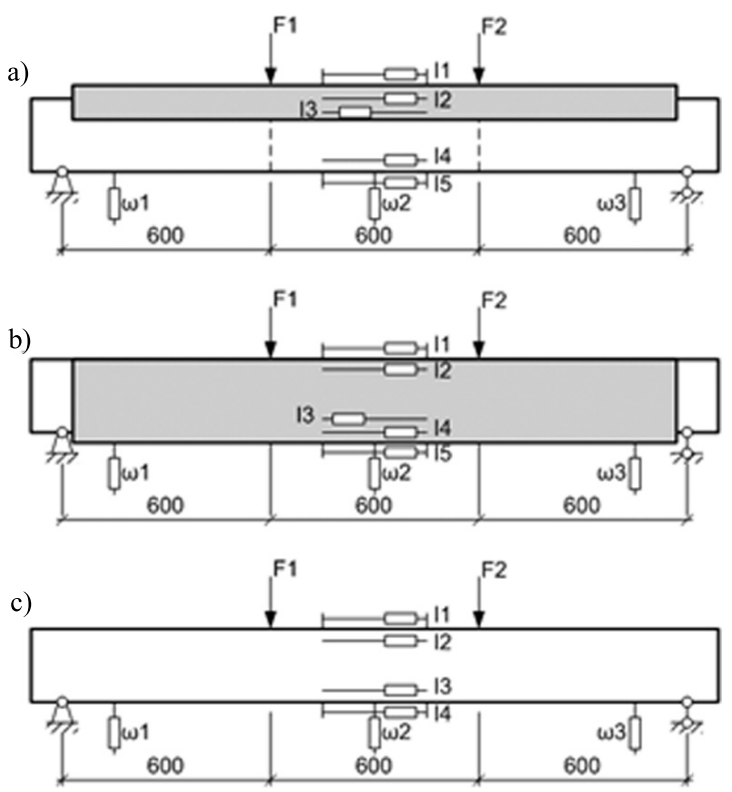

Fig. 6. Testing schema of the beams and arrangement of measuring devices: (a) SxT beams, (b) SxU beams, (c) Sx beams 
crete, respectively. The measurements were continuously recorded from the time the beams were loaded until failure. Measuring devices were attached only on one side of the façade of the beam, whereas on the other façade, cracking was observed through the total length of the span. The height of cracks was visually observed, and crack width was measured only at the level of the tensioned reinforcement.

\section{Numerical modelling}

All experimental beams were modelled applying for the finite element program DIANA. A nonlinear analysis was performed to determine models for the behaviour of finite elements. The beams were made from quadrilateral elements (Fig. 7), the dimensions of concrete elements were $16.67 \times 20 \times 20$ and the dimensions of HPFRCC elements were the same, except for the length, which amounted to $16.67-20 \mathrm{~mm}$. The size of the elements was determined by employing the method for testing errors. Models for smaller finite elements showed a better distribution of cracks that was more like in experimental beams but the load carrying capacity was about $30 \%$ smaller than experimental. Thus, the numerical analysis was completed using the above-mentioned dimensions of the elements. External loads were transferred through steel plates on the top of the beam, as described above. The beams were supported on steel plates that were given constraint conditions similar to those described in the previous section. The symmetry of the cross-section was evaluated. Only a half of the beam was modelled. The type of reinforcement mesh was "bar in solid". The program changed the stiffness of the quadrilateral element due to the embedded bar. Further, reinforcement elements can transfer only axial forces. The interface between reinforcement and concrete was not evaluated, and therefore, a perfect bond was assessed.

In order to perform a nonlinear analysis, the previously determined experimentally nonlinear stress-strain curves were used. The stress-strain curves of concrete and HPFRCC are shown in Figure 8a. These curves were obtained testing cylindrical samples (Fig. 5a). The tensile behaviour of HPFRCC is described by the curve presented in Figure 8b, which is analogical to the one displayed in Figure 5d. The stress-strain relation of tensioned ordinary concrete was described (Kaklauskas, Ghaboussi 2001) using the curve depicted in Figure 8c. The elasto-plastic behaviour of reinforcement was evaluated as shown in Figure 8d. All beams were loaded at the same load rate, which reached $4 \mathrm{kN}$.

\section{Experimental results}

\subsection{Deformability}

The distribution of strains across the height of the crosssection of the beam was derived during the experimental work. According to the strain value, stresses can be determined at a particular layer. Thus, the elastic, elasto-plastic or plastic behaviour of the layer material can be defined as well. Stress-strain relations were established by testing the samples of materials. Such relations can help with assessing stresses. If a slip between tensioned reinforcement and concrete is not evaluated, then, it is possible to determine that concrete strain is equal to reinforcement. The secant modulus of elasticity for concrete material was determined when the average strain was equal to $0.0424 \%$. Correspondingly, for the HPFRCC material, the average strain equalled $0.129 \%$. When strains in the com-
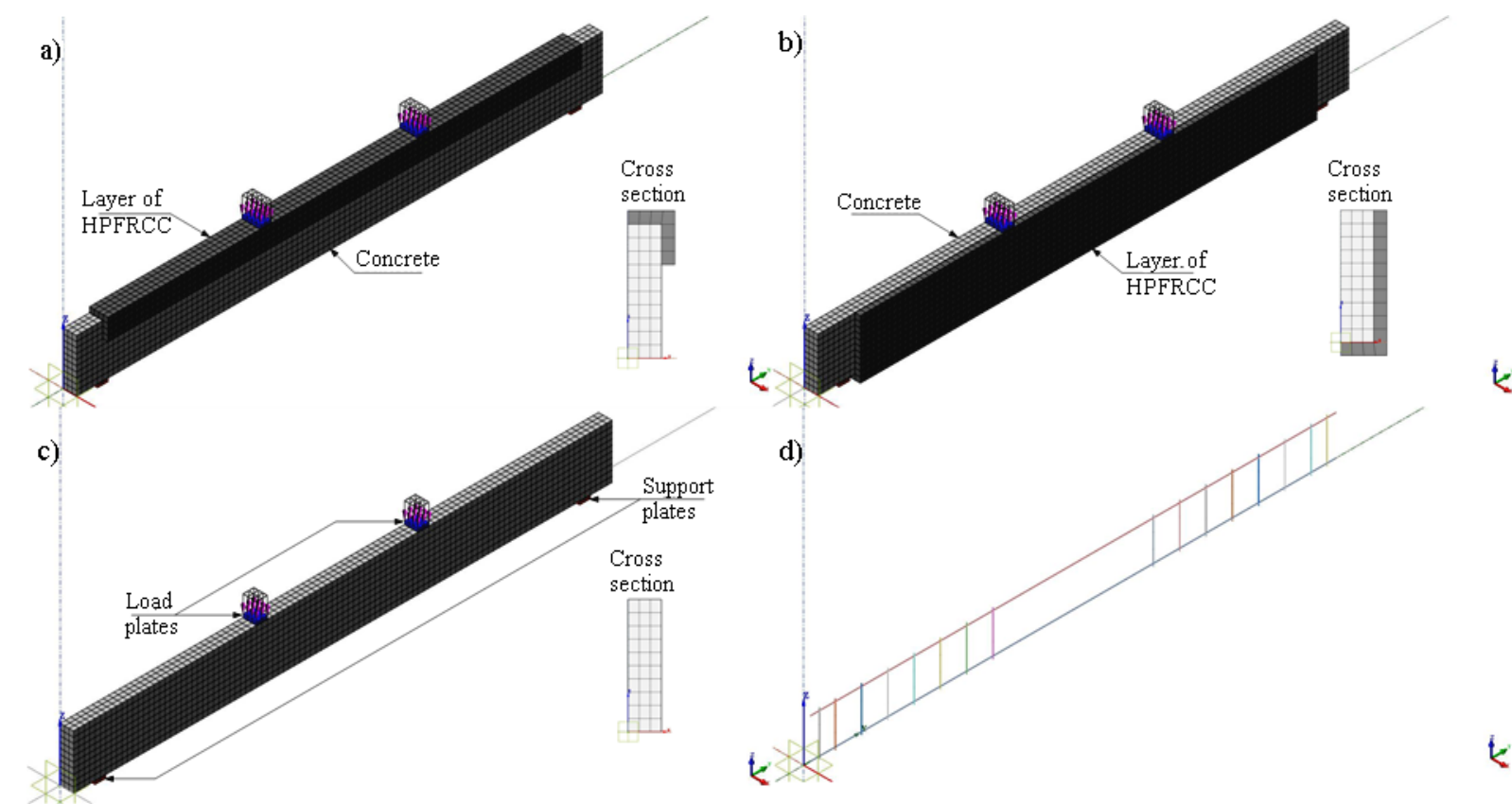

Fig. 7. Finite element models of the beams: (a) model of the SxT beams, (b) model of the SxU beams,

(c) model of the Sx beams, (d) model of the reinforcement carcass 


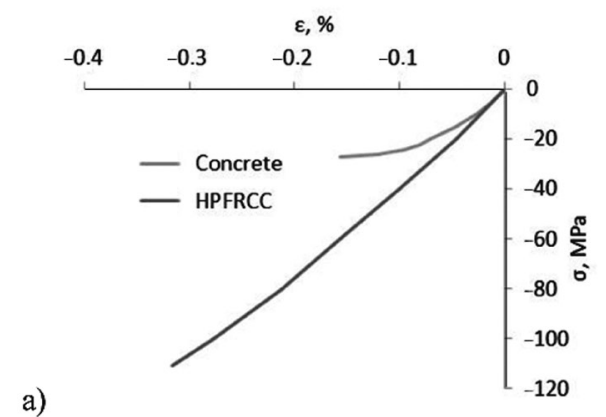

a)

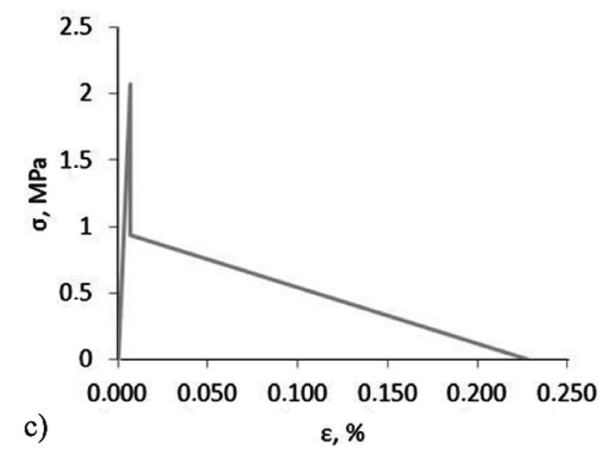

b)
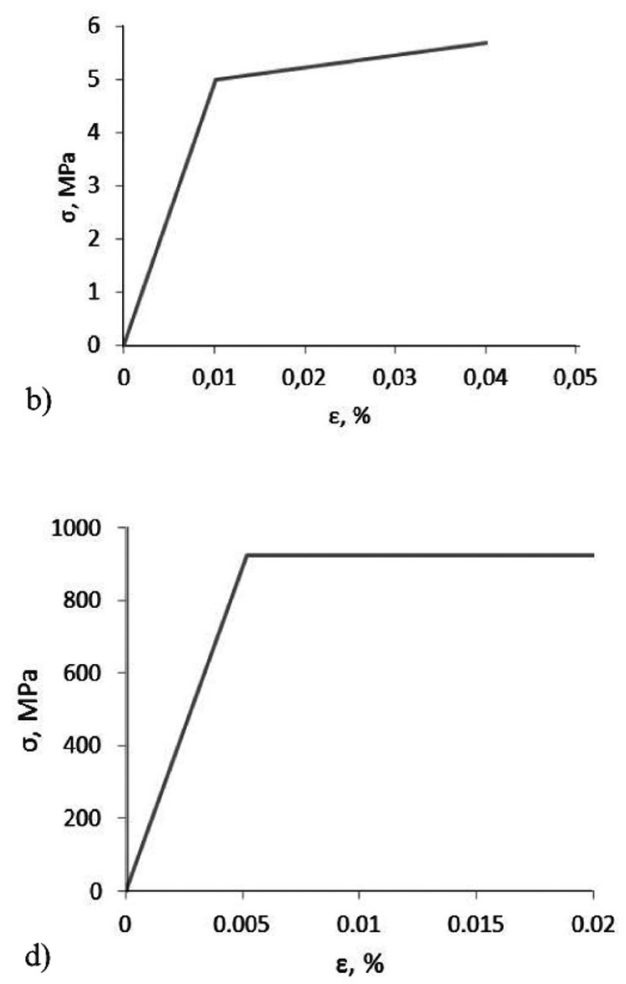

Fig. 8. Stress-strain curves evaluated in the finite element model: (a) compressed concrete and HPFRCC, (b) tensioned HPFRCC, (c) tensioned concrete, (d) reinforcement

pressed part of the sections of the beam reach the strain value of the concrete material, the bending moments in SxT, SxU and Sx beams are $17.1 \mathrm{kN} \cdot \mathrm{m}, 8.22 \mathrm{kN} \cdot \mathrm{m}$, and $5.07 \mathrm{kN} \cdot \mathrm{m}$, respectively. When strains in the compressed part of the sections of the beam reach the strain value of the HPFRCC material, the bending moment in $\mathrm{SxT}, \mathrm{SxU}$ and $\mathrm{Sx}$ beams is $48.83 \mathrm{kN} \cdot \mathrm{m}, 18.6 \mathrm{kN} \cdot \mathrm{m}$, and $13.19 \mathrm{kN} \cdot \mathrm{m}$, respectively. Although the developed strains in the compressed part of the section were in the elastic range, the tensioned part of the cross-section in all beams was cracked. The values of the selected strains, when an external load reaches $60 \%$ of load-carrying capacity, are presented in Tables 6,7 and 8. The values are given for compressed concrete, the HPFRCC layer and the tensioned layer with reinforcement. The bending moment is given in the second, fourth and sixth column of the tables, which corresponds to $60 \%$ of the maximum moment of Sx, SxU and SxT beams, respectively. When the bending moment reaches $60 \%$ of the maximum bending moment of Sx beams, the strains of the compressed concrete in SxT, SxU and Sx beams are in the elasto-plastic range. The strains of tensioned reinforcement show that, in all cases, the work of reinforcement was elastic. At the moment of failure, the plasticity of the compressed concrete was reached in SxU and Sx beams. As for SxT beams, only the plasticity of the HPFRCC material was reached, whereas in the compressed concrete layer, only elasto-plastic behaviour was observed. Table 9 presents strains in each layer at the moment of failure, at which Sx beams and strains of tensioned reinforcement show that reinforcement worked at the elastic stage, while those in SxT and SxU beams were at the elasto-plastic stage.

A comparison of experimentally and numerically determined strains and bending moment curves are presented in Figure 9. The curves derived from the compressed part of the section coincide. However, the coincidence of the curves of Sx beams disappears when the load reaches more than $60 \%$ of the load-carrying capacity. This was because the external load during the experiment was maintained for a particular time to identify cracking. At that moment, plastic deformations developed and experimental curves shifted from numerical curves. A comparison of the curves derived from the tensioned part was not as good as that in the compressed part. Sometimes, these curves coincide, but mostly, they do not. This is due to the fact that the number of cracks is not the same as in experimental beams.

The work of the compressed concrete changed because the sections of the strengthened beams were transformed after the application of new layers. This influenced the redistribution of internal stresses and forces. Compressive stresses in ordinary concrete in SxT beams decreased because an effective height (parameter d) of these beams increased, and the balance of internal forces requires a smaller depth of the neutral axis. Thus, a thinner concrete layer was occupied by the depth of the neutral axis. The height of SxU beams after strengthening also increased, but the effective height did not. The width 
Table 6. Strains of the layer with the tensioned steel bar when $M=0.6 \cdot M_{r}$

\begin{tabular}{c|c|c|c|c|c|c}
\hline Name & $\begin{array}{c}0.6 \cdot M_{r: S x}, \\
\mathrm{kN} \cdot \mathrm{m}\end{array}$ & $\varepsilon_{S}, \%$ & $\begin{array}{c}0.6 \cdot M_{r . S x U}, \\
\mathrm{kN} \cdot \mathrm{m}\end{array}$ & $\varepsilon_{S}, \%$ & $\begin{array}{c}0.6 \cdot M_{r . S x T}, \\
\mathrm{kN} \cdot \mathrm{m}\end{array}$ & $\varepsilon_{S}, \%$ \\
\hline $\mathrm{S} 1 \mathrm{~T}$ & 21.0 & 0.19145 & 32.14 & 0.2865 & $\mathbf{3 5 . 5}$ & $\mathbf{0 . 3 1 8 2 4}$ \\
\hline $\mathrm{S} 2 \mathrm{~T}$ & 21.0 & 0.1622 & 32.14 & 0.2561 & $\mathbf{3 4 . 5}$ & $\mathbf{0 . 2 7 7 3 5}$ \\
\hline $\mathrm{S} 3 \mathrm{~T}$ & 21.0 & 0.02776 & 32.11 & 0.3131 & $\mathbf{3 5 . 0}$ & $\mathbf{0 . 3 3 8 6 7}$ \\
\hline S4U & 21.0 & 0.17658 & $\mathbf{3 1 . 4}$ & $\mathbf{0 . 3 1 4 3}$ & 34.99 & 0.35791 \\
\hline S5U & 21.0 & 0.1602 & $\mathbf{3 3 . 8}$ & $\mathbf{0 . 2 8 9 1}$ & 34.99 & 0.30288 \\
\hline S6U & 21.0 & 0.196 & $\mathbf{3 1 . 2}$ & $\mathbf{0 . 3 2 7 3}$ & 35.05 & 0.3665 \\
\hline S7 & $\mathbf{2 0 . 6}$ & $\mathbf{0 . 2 5 1 3}$ & 32.11 & 0.4312 & 34.45 & 0.48079 \\
\hline S8 & $\mathbf{2 1 . 1}$ & $\mathbf{0 . 2 5 4 8}$ & 32.11 & 0.3862 & 35.14 & 0.46583 \\
\hline S9 & $\mathbf{2 1 . 2}$ & $\mathbf{0 . 2 2 0 4}$ & 32.11 & 0.3621 & 35.32 & 0.43387 \\
\hline
\end{tabular}

Table 7. Strains of the mostly compressed concrete layer when $M=0.6 \cdot M_{r}$

\begin{tabular}{c|c|c|c|c|c|c}
\hline Name & $\begin{array}{c}0.6 \cdot M_{r: S x}, \\
\mathrm{kN} \cdot \mathrm{m}\end{array}$ & $\varepsilon_{c}, \%$ & $\begin{array}{c}0.6 \cdot M_{r \cdot S x U}, \\
\mathrm{kN} \cdot \mathrm{m}\end{array}$ & $\varepsilon_{c}, \%$ & $\begin{array}{c}0.6 \cdot M_{r: S x T}, \\
\mathrm{kN} \cdot \mathrm{m}\end{array}$ & $\varepsilon_{c}, \%$ \\
\hline S1T & 21.0 & -0.04688 & 32.14 & -0.07855 & $\mathbf{3 5 . 5}$ & $\mathbf{- 0 . 0 8 3 0 4}$ \\
\hline S2T & 21.0 & -0.05679 & 32.14 & -0.09016 & $\mathbf{3 4 . 5}$ & $\mathbf{- 0 . 0 9 6 1 4}$ \\
\hline S3T & 21.0 & -0.05137 & 32.11 & -0.0808 & $\mathbf{3 5 . 0}$ & $-\mathbf{0 . 0 8 7 0 3}$ \\
\hline S4U & 21.0 & -0.11218 & $\mathbf{3 1 . 4}$ & $\mathbf{- 0 . 1 7 4 6 6}$ & 34.99 & -0.19275 \\
\hline S5U & 21.0 & -0.09483 & $\mathbf{3 3 . 8}$ & $-\mathbf{0 . 1 6 5 3 4}$ & 34.99 & -0.17132 \\
\hline S6U & 21.0 & -0.09825 & $\mathbf{3 1 . 2}$ & $-\mathbf{0 . 1 5 6 8 7}$ & 35.05 & -0.17336 \\
\hline S7 & $\mathbf{2 0 . 6}$ & $-\mathbf{0 . 1 5 1 6}$ & 32.11 & -0.38807 & 34.45 & -0.53041 \\
\hline S8 & $\mathbf{2 1 . 1}$ & $\mathbf{- 0 . 1 5 5 0}$ & 32.11 & -0.3031 & 35.14 & -0.41382 \\
\hline S9 & $\mathbf{2 1 . 2}$ & $\mathbf{- 0 . 1 6 2 1}$ & 32.11 & -0.3054 & 35.32 & -0.4356 \\
\hline
\end{tabular}

Table 8. Strains of the mostly compressed HPFRCC layer when $M=0.6 \cdot M_{r}$

\begin{tabular}{c|c|c|c|c|c|c}
\hline Name & $\begin{array}{c}0.6 \cdot M_{r . S x}, \\
\mathrm{kN} \cdot \mathrm{m}\end{array}$ & $\varepsilon_{c c}, \%$ & $\begin{array}{c}0.6 \cdot M_{r . S x U}, \\
\mathrm{kN} \cdot \mathrm{m}\end{array}$ & $\varepsilon_{c c}, \%$ & $\begin{array}{c}0.6 \cdot M_{r . S x T}, \\
\mathrm{kN} \cdot \mathrm{m}\end{array}$ & $\varepsilon_{c c}, \%$ \\
\hline $\mathrm{S} 1 \mathrm{~T}$ & 21.0 & -0.08191 & 32.14 & -0.12819 & $\mathbf{3 5 . 5}$ & $\mathbf{- 0 . 1 3 8 5 4}$ \\
\hline $\mathrm{S} 2 \mathrm{~T}$ & 21.0 & -0.08327 & 32.14 & -0.13239 & $\mathbf{3 4 . 5}$ & $\mathbf{- 0 . 1 4 0 4 4}$ \\
\hline $\mathrm{S} 3 \mathrm{~T}$ & 21.0 & -0.08145 & 32.11 & -0.12463 & $\mathbf{3 5 . 0}$ & $\mathbf{- 0 . 1 3 6 8 2}$ \\
\hline
\end{tabular}

Table 9. Maximal bending moment and strains at this moment

\begin{tabular}{|c|c|c|c|c|c|c|}
\hline Name & $\begin{array}{c}M_{\text {r.max }}, \\
\mathrm{kN} \cdot \mathrm{m}\end{array}$ & $\varepsilon_{c c}, \%$ & $\varepsilon_{c}, \%$ & $\varepsilon_{s}, \%$ & $\omega, \mathrm{mm}$ & Failure mode \\
\hline $\mathrm{S} 1 \mathrm{~T}$ & 59.14 & -0.2925 & -0.1426 & 0.9019 & 25.88 & \multirow{3}{*}{ Shear failure } \\
\hline S2T & 57.55 & -0.3143 & -0.1711 & 0.9407 & 27.44 & \\
\hline $\mathrm{S} 3 \mathrm{~T}$ & 58.3 & -0.2897 & -0.1673 & 0.9014 & 23.07 & \\
\hline S4U & 52.36 & - & -0.3556 & 0.8384 & 21.61 & \multirow{3}{*}{$\begin{array}{l}\text { Crushing of the compressed } \\
\text { concrete, shear failure }\end{array}$} \\
\hline S5U & 56.29 & - & -0.4453 & 1.0706 & 27.92 & \\
\hline S6U & 52.06 & - & -0.3679 & 0.998 & 22.33 & \\
\hline S7 & 34.35 & - & -0.5304 & 0.4808 & 19.26 & \multirow{3}{*}{$\begin{array}{l}\text { Crushing of the compressed } \\
\text { concrete }\end{array}$} \\
\hline S8 & 35.14 & - & -0.4138 & 0.4658 & 18.31 & \\
\hline S9 & 35.32 & - & -0.4365 & 0.4339 & 17.75 & \\
\hline
\end{tabular}



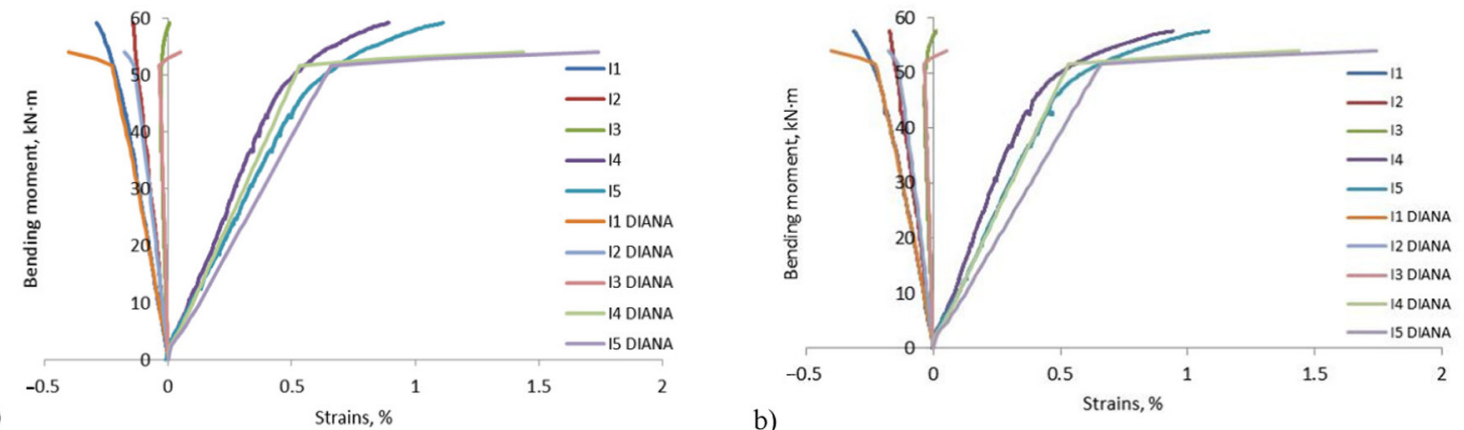

b)
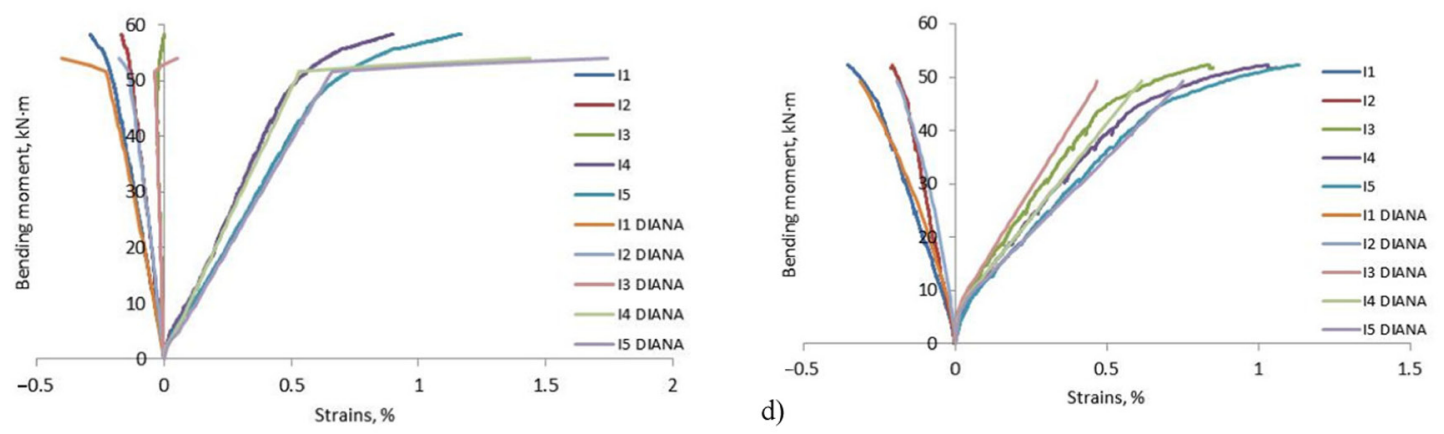

d)
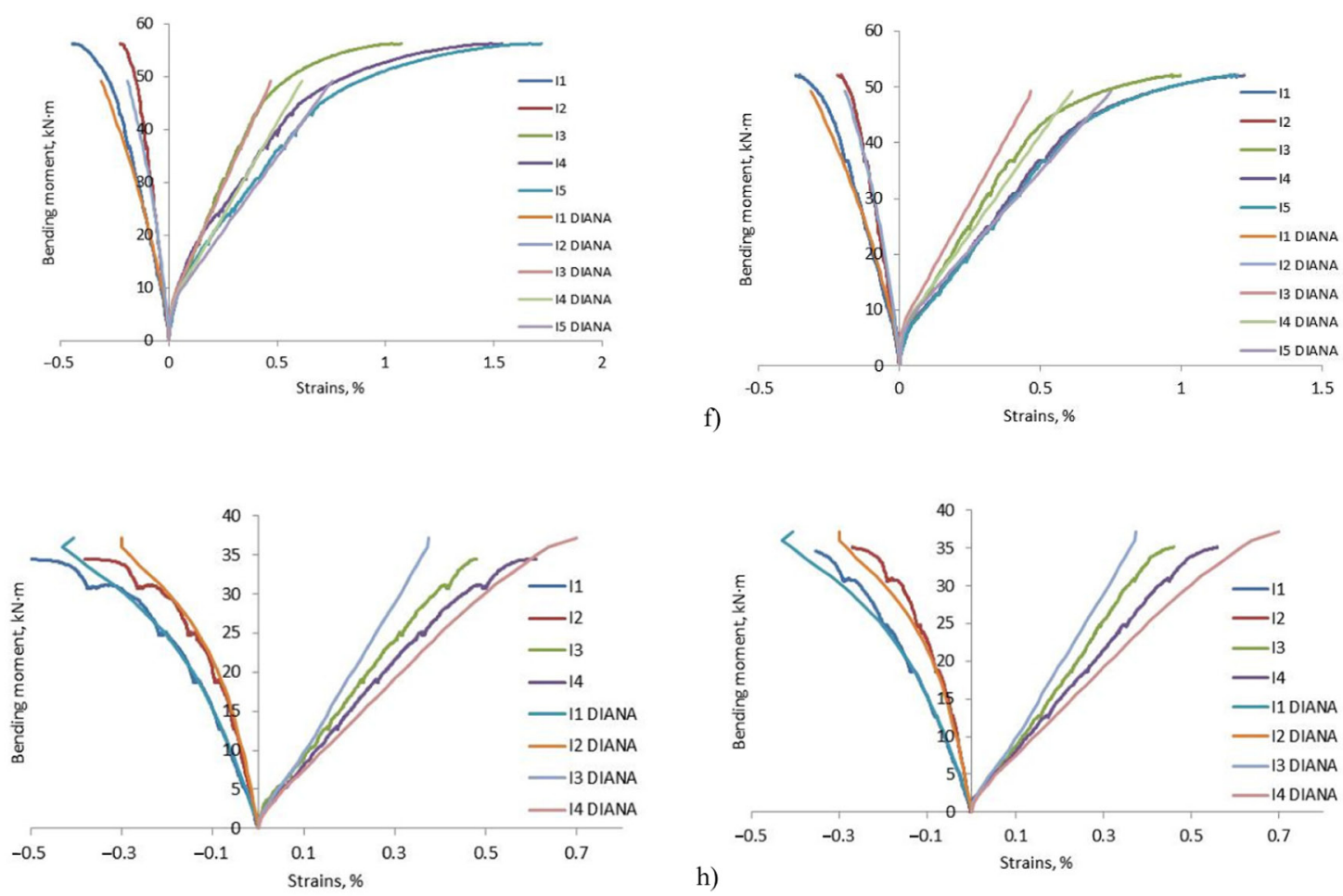

h)

Fig. 9. Bending moment and strains curves: (a) S1T beam, (b) S2T beam, (c) S3T beam, (d) S4U beam, (e) S5U beam, (f) S6U beam, (g) S7 beam, (h) S8 beam, (i) S9 beam 


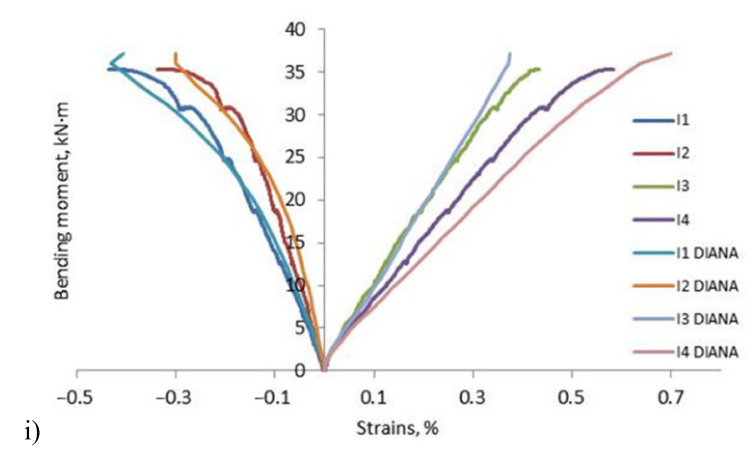

Fig. 9. Bending moment and strains curves: (i) S9 beam (Continued)

of the compressed part of these beams also increased. These aspects also ensured that the balance of internal forces could be maintained by a smaller height of the neutral axis, because the layer of the HPFRCC material can acquire a part of the resultant force from the compressed part of the cross-section. The evolution of the depth of the neutral axis of all beams was derived from the measured deformations and is presented in Figure 10.

This evolution shows that after the opening of the first vertical cracks, the depth of the neutral axis in SxT and $\mathrm{Sx}$ beams decreases rapidly, while that of SxU beams decreases to a small extent. The decrease was not rapid because the contribution of fibres (in the crack) remained less than the value of the resultant force in the tensioned part of the cross-section, and this demanded a greater depth of the neutral axis. The resultant force in the tensioned and compressed parts of the cross-section in these beams consists of two parts. The resultant force in the compressed part is the sum of resulting forces in concrete and HPFRCC. The resultant force in the tensioned part is the sum of resultant forces of reinforcement and fibres (in the crack). The ratio between the resultant forces of each part can change. When the crack width increases, the tensile carrying capacity of fibre decreases, because the pull-out process can start, and then, the resultant force decreases in the tensioned HPFRCC and increases in steel bars. The lever arm between resultant forces in the compressed and tensioned parts slightly increases; consequently, the depth of the neutral axis decreases. This decrease, as mentioned earlier, has occurred because the compressed HPFRCC layer can take a part of the resultant force. After the opening of vertical cracks, the depth of the neutral axis in SxT beams is constant until the tensioned steel bar start expressing elasto-plastic behaviour. The depth of the neutral axis in SxU beams gradually decreases until the tensioned steel bars commence with elasto-plastic behaviour.

The depth of the neutral axis in Sx beams increases, because these beams were over-reinforced, and the balance of internal forces requires a greater depth of the neutral axis. When the resultant force of tensioned reinforcement increases, the resultant force of the compressed concrete must also increase. The resultant forces of the compressed concrete increase along with a growing depth of the neutral axis. If the depth of the neutral axis is really great, the ultimate compressive strength can be reached earlier than the tensile strength of steel bars. Sx beams failed when concrete in the compressed part of the crosssection was crushed. a)

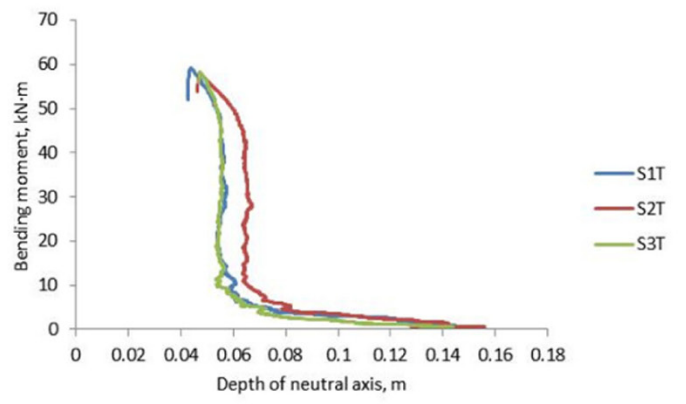

c)

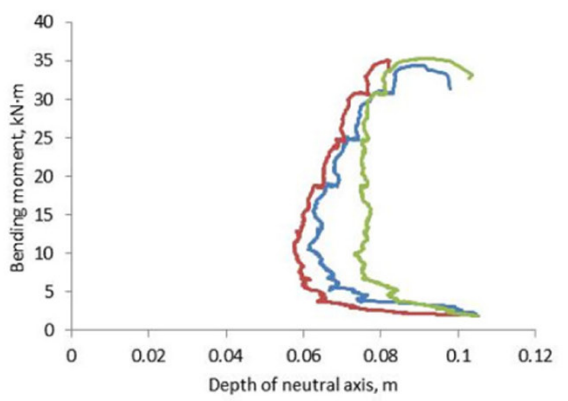

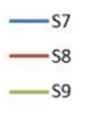

Fig. 10. Variation of the depth of the neutral axis: (a) SxT beams, (b) SxU beams, (c) Sx beams; (d) comparison between the S1T, S4U, and S7 beams

d)
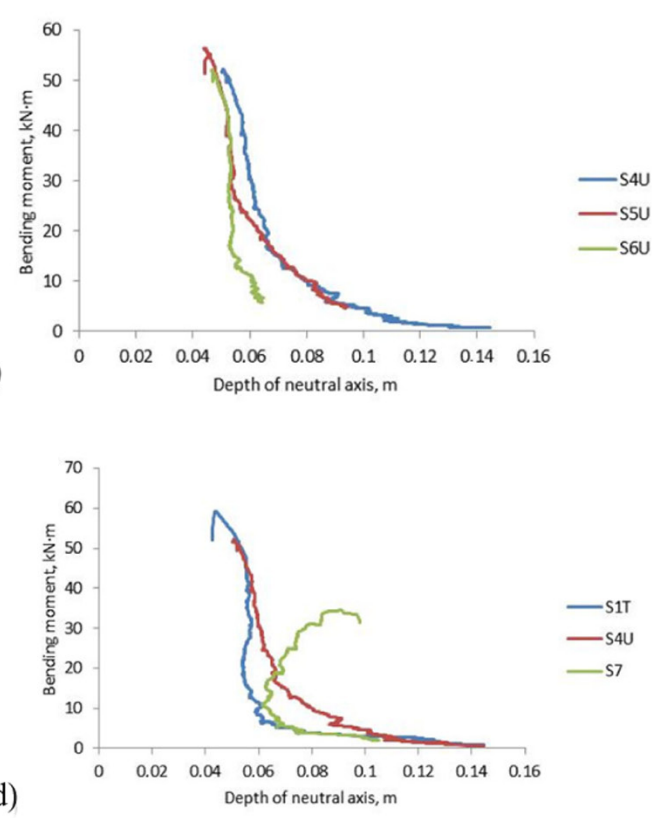


\subsection{Cracking}

A positive and negative effect of strengthening was determined by the cracking manner of the strengthened beams. A cracking moment of the strengthened beams increased or remained the same (Table 10). The number of cracks, the distance between the cracks, the height, the development direction and the width of the cracks changed. The cracks were observed through the span length of the beam and were divided into two groups. Parameters for all observed cracks are presented in Table 11. Parameters for the cracks observed in the pure bending region and in the area of acting shear forces are presented in Tables 12 and 13 . The presented value corresponds with the maximum width of the crack, the quantity of cracks and a sum of the width of all cracks. The width was measured at the level of tensioned reinforcement.

The maximum quantity of opened cracks was observed in Sx beams and the minimum quantity was found in SxU beams. However, the observed width of the crack in $\mathrm{SxU}$ beams was the greatest among the beams. Besides, the distance between cracks was also the largest in these beams. The tensile strength of HPFRCC and the ultimate strain of rupture were larger than those of ordinary concrete. Therefore, the amount of energy required
Table 10. Cracking moment of the beams

\begin{tabular}{c|c}
\hline Name & $M_{c r c}, \mathrm{kN} \cdot \mathrm{m}$ \\
\hline $\mathrm{S} 1 \mathrm{~T}$ & 5.2 \\
\hline $\mathrm{S} 2 \mathrm{~T}$ & 3.7 \\
\hline $\mathrm{S} 3 \mathrm{~T}$ & 11.2 \\
\hline $\mathrm{S} 4 \mathrm{U}$ & 3.7 \\
\hline $\mathrm{S} 5 \mathrm{U}$ & 3.7 \\
\hline $\mathrm{S} 6 \mathrm{U}$ & 6.7 \\
\hline $\mathrm{S} 7$ & 3.7 \\
\hline $\mathrm{S} 8$ & 3.7 \\
\hline S9 & 3.7
\end{tabular}

to reach the rupture was greater, and accordingly, the distance between the rupture locations increased. Ordinary concrete requires less energy to reach rupture; therefore, the distance between cracks in SxT and Sx beams was smaller. The observed cracks were marked on the facade of the beam and presented in Figures 11, 12, and 13.

\subsection{Deflections}

The bending stiffness of the beams was increased after strengthening. Generally, growth in bending stiffness was influenced by an increase in the cross-section and the re-

Table 11. Parameters of the cracks: maximal width, quantity, sum of the cracks width

\begin{tabular}{|c|c|c|c|c|c|}
\hline \multirow[b]{2}{*}{ Name } & $M=18 \mathrm{kN} \cdot \mathrm{m}$ & $M=24 \mathrm{kN} \cdot \mathrm{m}$ & $M=30 \mathrm{kN} \cdot \mathrm{m}$ & $M=36 \mathrm{kN} \cdot \mathrm{m}$ & $M=42 \mathrm{kN} \cdot \mathrm{m}$ \\
\hline & $\begin{array}{c}w_{\max }, \operatorname{mm} \text { (quant.) } \\
\Sigma w, \mathrm{~mm}\end{array}$ & $\begin{array}{c}w_{\max }, \operatorname{mm} \text { (quant.) } \\
\Sigma w, \mathrm{~mm}\end{array}$ & $\begin{array}{c}w_{\max }, \operatorname{mm} \text { (quant.) } \\
\Sigma w, \mathrm{~mm}\end{array}$ & $\begin{array}{c}w_{\max }, \operatorname{mm} \text { (quant.) } \\
\Sigma w, \mathrm{~mm}\end{array}$ & $\begin{array}{c}w_{\max }, \operatorname{mm} \text { (quant.) } \\
\Sigma w, \mathrm{~mm}\end{array}$ \\
\hline S1T & 0.1 (19) 1.0 & $0.1(24) 1.375$ & $0.2(27) 2.275$ & 0.2 (28) 2.7 & $0.25(28) 3.575$ \\
\hline $\mathrm{S} 2 \mathrm{~T}$ & 0.15 (21) 1.225 & 0.2 (24) 1.85 & 0.25 (27) 2.525 & $0.3(31) 3.475$ & $0.4(32) 4.7$ \\
\hline S3T & 0.1 (10) 0.625 & 0.1 (13) 1.05 & 0.2 (18) 1.8 & 0.25 (26) 3.1 & $0.3(26) 4.15$ \\
\hline $\mathrm{S} 4 \mathrm{U}$ & 0.25 (15) 1.075 & 0.35 (19) 1.9 & 0.55 (19) 2.925 & 0.65 (21) 3.925 & \\
\hline $\mathrm{S} 5 \mathrm{U}$ & 0.15 (13) 0.95 & 0.25 (19) 1.6 & 0.30 (20) 2.25 & $0.4(26) 3.225$ & \\
\hline S6U & 0.125 (16) 0.85 & 0.2 (16) 1.475 & 0.25 (19) 2.1 & $0.3(20) 2.925$ & \\
\hline S7 & 0.2 (18) 1.4 & $0.25(27) 2.425$ & $0.35(29) 3.625$ & & \\
\hline S8 & 0.125 (22) 1.15 & 0.2 (29) 2.2 & $0.3(32) 3.25$ & & \\
\hline S9 & 0.15 (24) 1.45 & $0.2(28) 2.175$ & $0.3(28) 2.85$ & & \\
\hline
\end{tabular}

Table 12. Parameters of the cracks from the pure bending region: maximal width, quantity, sum of the cracks width

\begin{tabular}{|c|c|c|c|c|c|}
\hline \multirow[b]{2}{*}{ Name } & $M=18 \mathrm{kN} \cdot \mathrm{m}$ & $M=24 \mathrm{kN} \cdot \mathrm{m}$ & $M=30 \mathrm{kN} \cdot \mathrm{m}$ & $M=36 \mathrm{kN} \cdot \mathrm{m}$ & $M=42 \mathrm{kN} \cdot \mathrm{m}$ \\
\hline & $\begin{array}{c}w_{\max }, \operatorname{mm} \text { (quant.) } \\
\Sigma w, \mathrm{~mm}\end{array}$ & $\begin{array}{c}w_{\max }, \operatorname{mm} \text { (quant.) } \\
\Sigma w, \operatorname{mm}\end{array}$ & $\begin{array}{c}w_{\max }, \operatorname{mm} \text { (quant.) } \\
\Sigma w, \mathrm{~mm}\end{array}$ & $\begin{array}{c}w_{\max }, \operatorname{mm} \text { (quant.) } \\
\Sigma w, \mathrm{~mm}\end{array}$ & $\begin{array}{c}w_{\max }, \operatorname{mm} \text { (quant.) } \\
\Sigma w, \mathrm{~mm}\end{array}$ \\
\hline S1T & $0.1(10) 0.625$ & 0.1 (11) 0.8 & 0.2 (11) 1.15 & 0.2 (12) 1.475 & 0.25 (12) 1.775 \\
\hline $\mathrm{S} 2 \mathrm{~T}$ & $0.15(10) 0.825$ & $0.2(11) 1.25$ & 0.25 (11) 1.525 & 0.3 (11) 1.975 & 0.4 (11) 2.5 \\
\hline S3T & 0.1 (7) 0.55 & $0.1(8) 0.75$ & $0.2(8) 1.15$ & $0.25(8) 1.45$ & 0.275 (8) 1.8 \\
\hline S4U & 0.25 (6) 0.65 & $0.3(8) 0.9$ & 0.45 (8) 1.35 & $0.6(8) 1.8$ & \\
\hline S5U & $0.15(7) 0.6$ & $0.25(8) 0.95$ & $0.3(8) 1.375$ & $0.4(8) 1.875$ & \\
\hline S6U & $0.125(8) 0.55$ & $0.2(8) 0.875$ & 0.25 (10) 1.15 & 0.3 (10) 1.5 & \\
\hline S7 & $0.15(8) 0.725$ & 0.2 (11) 1.275 & 0.275 (11) 1.95 & & \\
\hline S8 & 0.075 (11) 0.65 & $0.2(12) 1.2$ & $0.3(12) 1.7$ & & \\
\hline S9 & 0.15 (11) 0.8 & 0.2 (11) 1.075 & 0.3 (11) 1.425 & & \\
\hline
\end{tabular}


Table 13. Parameters of the cracks from the regions where shear forces act: maximal width, quantity, sum of the cracks width

\begin{tabular}{c|c|c|c|c|c}
\hline \multirow{2}{*}{ Name } & $M=18 \mathrm{kN} \cdot \mathrm{m}$ & $M=24 \mathrm{kN} \cdot \mathrm{m}$ & $M=30 \mathrm{kN} \cdot \mathrm{m}$ & $M=36 \mathrm{kN} \cdot \mathrm{m}$ & $M=42 \mathrm{kN} \cdot \mathrm{m}$ \\
\cline { 2 - 6 } & $\begin{array}{c}w_{\max }, \mathrm{mm}(\mathrm{quant}) \\
\Sigma w, \mathrm{~mm}\end{array}$ & $\begin{array}{c}w_{\max }, \mathrm{mm}(\mathrm{quant}) \\
\Sigma w, \mathrm{~mm}\end{array}$ & $\begin{array}{c}w_{\max }, \mathrm{mm} \text { (quant.) } \\
\Sigma w, \mathrm{~mm}\end{array}$ & $\begin{array}{c}w_{\max }, \mathrm{mm} \text { (quant.) } \\
\Sigma w, \mathrm{~mm}\end{array}$ & $\begin{array}{c}w_{\max }, \mathrm{mm}(\mathrm{quant} .) \\
\Sigma w, \mathrm{~mm}\end{array}$ \\
\hline S1T & $0.1(9) 0.375$ & $0.1(13) 0.575$ & $0.15(16) 1.125$ & $0.15(16) 1.225$ & $0.25(16) 1.8$ \\
\hline S2T & $0.075(11) 0.4$ & $0.1(13) 0.6$ & $0.15(16) 1.0$ & $0.2(20) 1.5$ & $0.25(21) 2.2$ \\
\hline S3T & $0.05(3) 0.075$ & $0.1(5) 0.3$ & $0.15(10) 0.65$ & $0.15(18) 1.65$ & $0.3(18) 2.35$ \\
\hline S4U & $0.15(9) 0.425$ & $0.35(11) 1.0$ & $0.55(11) 1.575$ & $0.65(13) 2.125$ & \\
\hline S5U & $0.1(6) 0.35$ & $0.15(11) 0.65$ & $0.15(12) 0.875$ & $0.25(18) 1.35$ & \\
\hline S6U & $0.075(8) 0.3$ & $0.15(8) 0.6$ & $0.25(9) 0.95$ & $0.3(10) 1.425$ & \\
\hline S7 & $0.2(10) 0.675$ & $0.25(16) 1.15$ & $0.35(18) 1.675$ & & \\
\hline S8 & $0.125(11) 0.5$ & $0.2(17) 1.0$ & $0.2(20) 1.55$ & & \\
\hline S9 & $0.1(13) 0.65$ & $0.2(17) 1.1$ & $0.3(17) 1.425$ & & \\
\hline
\end{tabular}

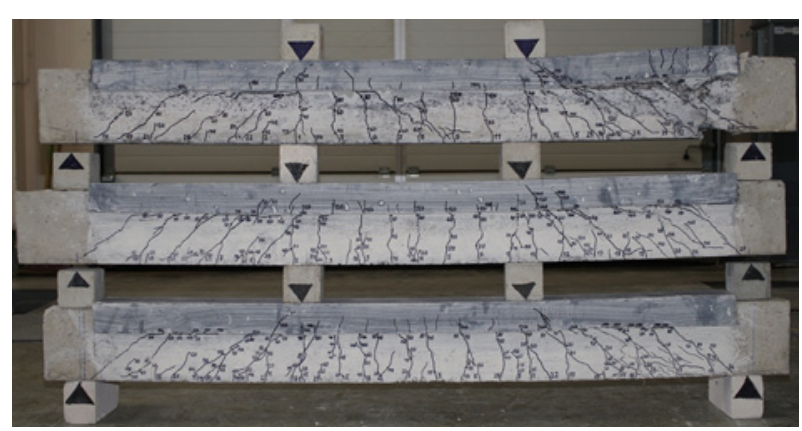

Fig. 11. Marked cracks on the S1T, S2T, and S3T beams (from the bottom)

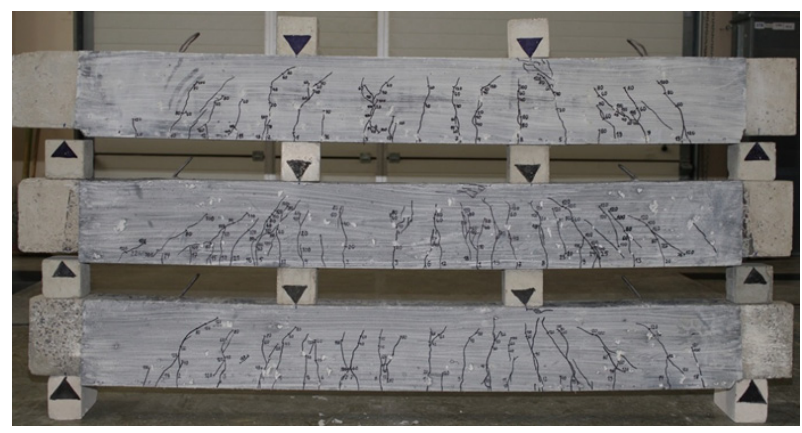

Fig. 12. Marked cracks on the S4T, S5T, and S6T beams (from the top)

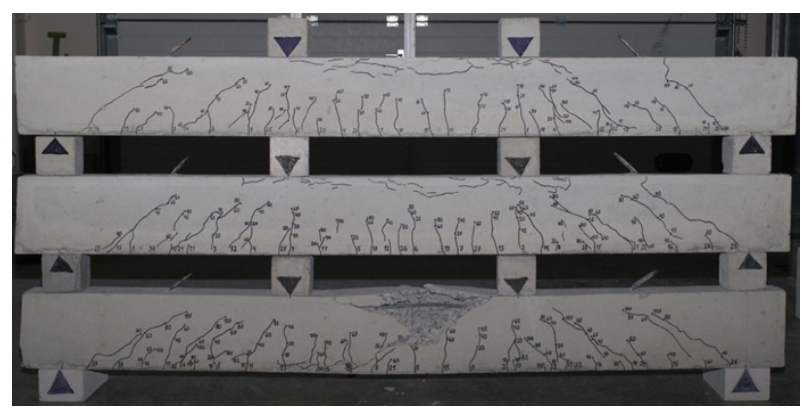

Fig. 13. Marked cracks on the S7, S8, and S9 beams (from the top) maining tensile strength of the HPFRCC material; at a later stage, the material cracks. The curves of experimentally and numerically determined deflection and the bending moment are compared in Figure 14. A linear and nonlinear increment of deflection can be distinguished from this comparison. A tendency towards the linear and nonlinear increment coincides with the linear and nonlinear increment of deformations.

It is possible to expect the moment of cracking in all deflection bending moment curves. After opening the first vertical crack, an increment of deflection in SxT and Sx beams rapidly increases. It is possible to expect a braking point on the curves. However, the increment of deflection in $\mathrm{SxU}$ beams is a little slower. The tensile part of the cross-section of these beams is composed of two materials: concrete and HPFRCC. The conducted experiments determined that the ultimate tensile deformation of concrete was smaller than that of the HPFRCC material. The first crack will open in the internal concrete layer and only later in the HPFRCC layer. The tensile strength of the HPFRCC material, after crack opening, can increase to some extent due to the fibres intercepting tensile force. Therefore, such parabolic increment in deflection after the opening of the first vertical cracks can be explained by the tension-stiffening ability of the HPFRCC material. The experimentally determined deflection and bending moment curves of all beams are compared in Figure 15. The curves of S1T, S4U and S7 beams are compared in Figures $14 \mathrm{~d}$ and $15 \mathrm{~d}$, which show it is possible to expect a parabolic part on the curve of S4U beams.

After the opening of vertical cracks, the increment of deflection in SxT beams becomes constant, and that of deflection in SxU beams becomes constant; thereafter, the number of vertical cracks does not increase (Table 11). The increment of deflection in Sx beams is not constant until the failure. Generally, the increment of deflection can be explained by a change in bending stiffness, which, however, can be explained by a change in the position of the neutral axis (Fig. 10) and the evolution of cracks (Tables 11, 12 and 13; Figs 11, 12 and 13). The evolu- 

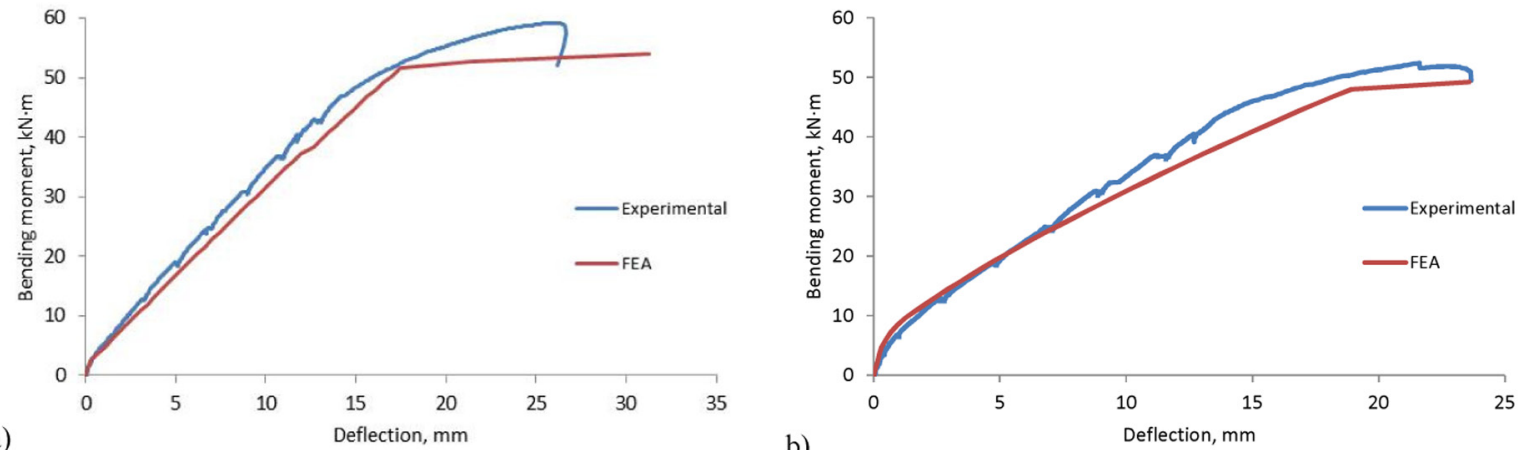

b)
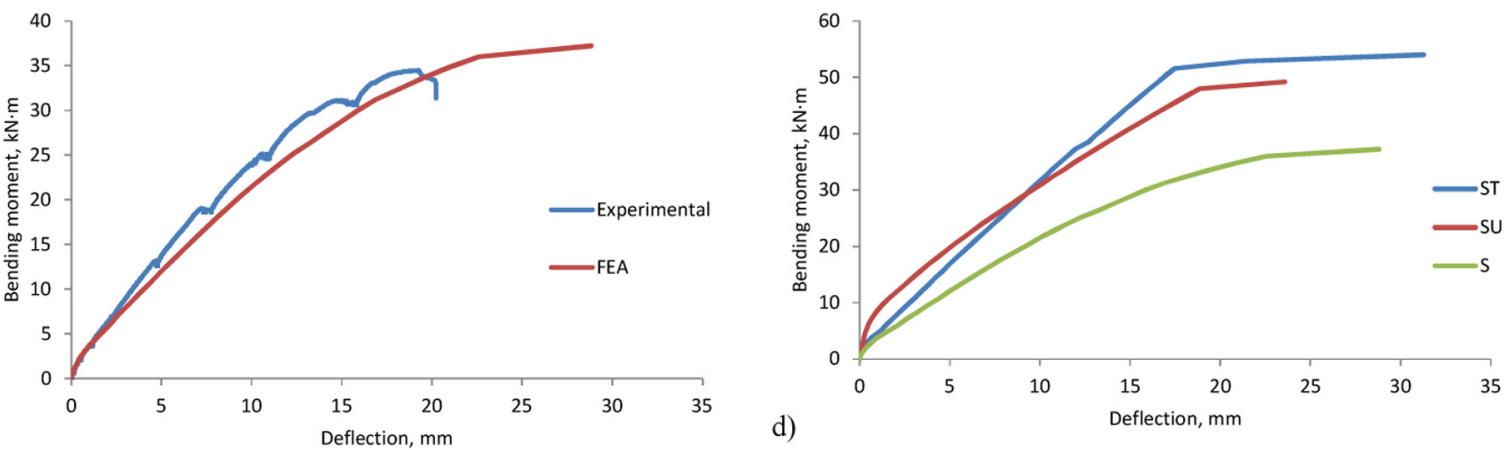

Fig. 14. Comparison of experimentally and numerically predicted deflection: (a) SxT beams, (b) SxU beams, (c) Sx beams, (d) comparison of numerically predicted deflections of the SxT, SxU, and Sx beams

a)
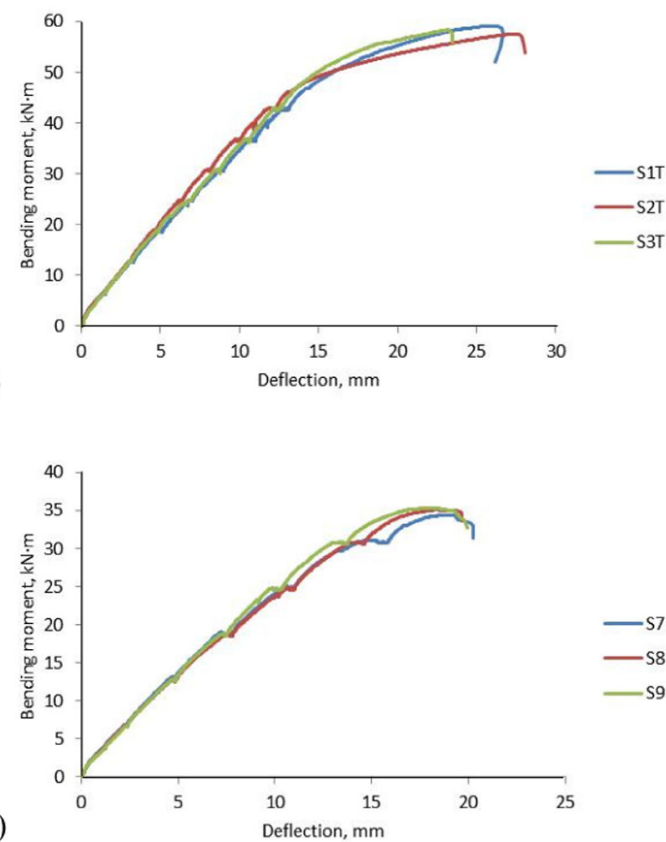

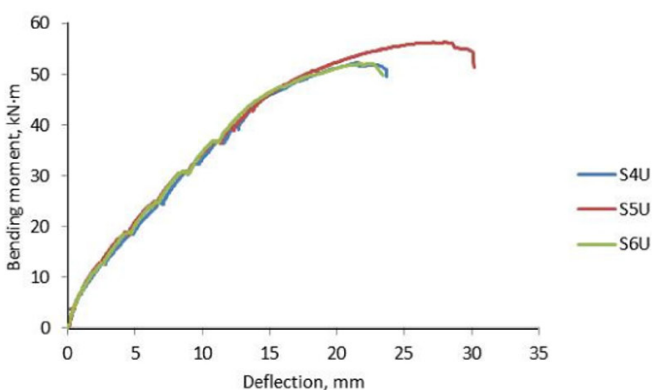

b)

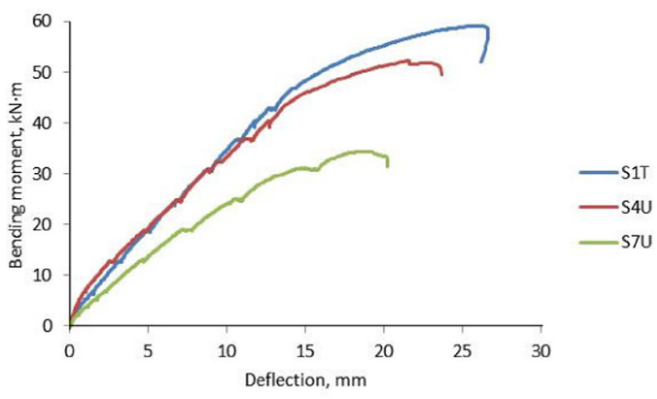

Fig. 15. Experimentally predicted deflections: (a) S1T, S2T, and S3T beams, (b) S4U, S5U, and S6U beams, (c) S7, S8, and S9 beams, (d) comparison of experimentally predicted deflection of the S1T, S4U, S7 beams 
Table 14. Deflection of the beams when $M=0.6 \cdot M_{r}$

\begin{tabular}{c|c|c|c|c|c|c|c|c|c}
\hline Name & $\begin{array}{c}0.6 \cdot M_{r . S x}, \\
\mathrm{kN} \cdot \mathrm{m}\end{array}$ & $\omega, \mathrm{mm}$ & $\omega / \omega_{u l}$ & $\begin{array}{c}0.6 \cdot M_{r: S x U}, \\
\mathrm{kN} \cdot \mathrm{m}\end{array}$ & $\omega, \mathrm{mm}$ & $\omega / \omega_{u l}$ & $\begin{array}{c}0.6 \cdot M_{r: S x T}, \\
\mathrm{kN} \cdot \mathrm{m}\end{array}$ & $\omega, \mathrm{mm}$ & $\omega / \omega_{u l}$ \\
\hline S1T & 21.0 & 5.62 & 0.412 & 32.14 & 9.26 & 0.679 & $\mathbf{3 5 . 5}$ & $\mathbf{1 0 . 2 2}$ & 0.749 \\
\hline S2T & 21.0 & 5.13 & 0.376 & 32.14 & 8.43 & 0.618 & $\mathbf{3 4 . 5}$ & $\mathbf{9 . 0 2}$ & 0.661 \\
\hline S3T & 21.0 & 5.31 & 0.389 & 32.11 & 9.0 & 0.660 & $\mathbf{3 5 . 0}$ & $\mathbf{9 . 7 2}$ & 0.713 \\
\hline S4U & 21.0 & 5.49 & 0.402 & $\mathbf{3 1 . 4}$ & $\mathbf{9 . 1 6}$ & 0.672 & 34.99 & 10.53 & 0.772 \\
\hline S5U & 21.0 & 5.05 & 0.370 & $\mathbf{3 3 . 8}$ & $\mathbf{9 . 7 6}$ & 0.716 & 34.99 & 10.19 & 0.747 \\
\hline S6U & 21.0 & 5.21 & 0.382 & $\mathbf{3 1 . 2}$ & $\mathbf{9 . 1 2}$ & 0.669 & 35.05 & 10.1 & 0.740 \\
\hline S7 & $\mathbf{2 0 . 6}$ & $\mathbf{8 . 3 3}$ & 0.611 & 32.11 & 16.18 & 1.186 & 34.45 & 19.26 & 1.412 \\
\hline S8 & $\mathbf{2 1 . 1}$ & $\mathbf{8 . 6 7}$ & 0.636 & 32.11 & 15.09 & 1.106 & 35.14 & 18.31 & 1.342 \\
\hline S9 & $\mathbf{2 1 . 2}$ & $\mathbf{8 . 2 8}$ & 0.607 & 32.11 & 14.19 & 1.040 & 35.32 & 17.75 & 1.301 \\
\hline
\end{tabular}

tion of the depth of the neutral axis and cracks shows that the bending stiffness of SxU beams is the highest. This is because the depth of the neutral axis was the highest, and the length of cracks was the smallest. Therefore, the deflection of these beams is smaller in comparison with those of SxT beams. However, the depth of the neutral axis becomes similar along with the deflection of the beams which also increases at a later stage. The centre of gravity in the cross-section of $\mathrm{SxU}$ beams is located lower than that in SxT beams; therefore, the deflection increment becomes greater.

The deflection of beams SxT and SxU increases until reinforcement enters into the elasto-plastic work stage. Then, the curvature of these beams catastrophically increases. SxT beams fail while shear force cuts off the flange of the cross-section. SxU beams fail first while the compressive strength of the upper concrete layer is reached due to large curvature. An external load of these beams increases until the compressive strength of HPFRCC is reached. A failure in models for finite elements occurred while the plasticity of reinforcement was reached, because, only the elastic and then the plastic behaviour of reinforcement was evaluated in the FEM model. A failure in Sx beams was governed by crushing concrete in the compressed part of the section in both the experimental test and the FEM model.

The experimentally determined deflection of all beams was compared with ultimate deflection (Table 14) determined by the interpolation of ultimate deflection ranged between the span length and of 1 meter and 3 meters. This comparison was made with reference to deflection values, which corresponds to $60 \%$ of load-carrying capacity.

\section{Conclusions}

The following conclusions of the study on the behaviour of the strengthened beams can be drawn:

1. Ultimate deformations of the HPFRCC material are greater than those of ordinary concrete. When the maximum stress is reached in the concrete lay- er, stresses in the HPFRCC layer do not reach its strength.

2. HPFRCC layers applied on the compressed part of the cross-section decreased stresses in the compressed concrete layer. Thus, the bending stiffness increased not only due to the increased cross-section but also due to the decreased evolution of plastic deformations in the concrete layer. Further, bending stiffness increased due to the remaining tensile strength of the HPFRCC material, after which this material cracks.

3. After strengthening, the position of internal forces changed. Internal forces of the compressed part distributed in concrete and the HPFRCC layer. Internal forces of the tensioned part distributed in concrete, the HPFRCC material layer and reinforcement.

4. The comparison of experimentally and numerically determined strains in the compressed part of the cross-section is in very good agreement.

5. A change in bending stiffness can be explained by a change in the position of the neutral axis and the evolution of cracks. If the depth of the neutral axis remains constant, the increment in deflection is constant.

6. The contribution of fibres in the tensioned part of the cross-section leads to a slight decrease in the depth of the neutral axis, which positively influences a change in bending stiffness.

7. A positive and negative effect of strengthening was determined. The cracking moment of the strengthened beams increased or remained the same. The width of a vertical crack not only decreased but also increased after strengthening. Thus, this research has showed that strengthening the tensioned part of the section does not guarantee that the width of cracks will be smaller.

\section{Acknowledgements}

The authors would like to thank Tecnochem Italiana S.p.A and UAB "Alu systems" for the supply of the HPFRCC material and technical support. 


\section{References}

Brühwiler, E.; Denarié, E. 2013. Rehabilitation of concrete structures using ultra-high performance fibre reinforced concrete, Structural Engineering International 23(4): $450-457$. http://dx.doi.org/10.2749/101686613X13627347100437

Cai, X.; Xu, S. 2011. Uniaxial compressive properties of ultra high toughness cementitious composite, Journal of Wuhan University of Technology-Materials Science Edition 26(4): 762-769. http://dx.doi.org/10.1007/s11595-011-0307-0

Ćirović, G.; Radonjanin, V.; Trivunić, M.; Nikolić, D. 2014. Optimization of UHPFRC beams subjected to bending using genetic algorithms, Journal of Civil Engineering and Management 20(4): 527-536.

http://dx.doi.org/10.3846/13923730.2013.801908

Daugevičius, M.; Valivonis, J. 2013. Axially loaded concrete and reinforced concrete elements strengthened with HPFRCC, in Fiber Concrete, 12-13 September 2013, Prague, Czech Republic. 10 p.

Daugevičius, M.; Valivonis, J.; Marčiukaitis, G. 2012. Deflection analysis of reinforced concrete beams strengthened with carbon fibre reinforced polymer under long-term load action, Journal of Zhejiang University-SCIENCE A (Applied Physics \& Engineering) 13(8): 571-583.

Elsanadedy, H. M.; Almusallam, T. H.; Alsayed, S. H.; Al-Salloum, Y. A. 2013. Flexural strengthening of RC beams using textile reinforced mortar - experimental and numerical study, Composite Structures 97: 40-55.

http://dx.doi.org/10.1016/j.compstruct.2012.09.053

EN 12390-3 Testing hardened concrete - Part 3: Compressive strength of test specimens. European standard. European Committee for Standardization, Brussels, 2009.

EN 12390-5 Testing hardened concrete - Part 5: Flexural strength of test specimens. European standard. European Committee for Standardization, Brussels, 2009.

EN 13412 Products and systems for the protection and repair of concrete structures - Test methods - Determination of modulus of elasticity in compression. European standard. European Committee for Standardization, Brussels, 2006.

EN 14651 Test method for metallic fiber concrete - measuring the flexural tensile strength (limit of proportionality (LOP), residual). European standard. European Committee for Standardization, Brussels, 2005.

ISO 15630 Steel for the reinforcement and prestressing of concrete - Test methods - Part 1: Reinforcing bars, wire rod and wire. International standard. International Organization for Standardization, Geneva, 2002.

Farhat, F. A.; Nicolaides, D.; Kanellopoulos, A.; Karihaloo, B. L. 2007. High performance fiber-reinforced cementitious composite (CARDIFRC) - Performance and application to retrofitting, Engineering Fracture Mechanics 74(1-2): $151-167$. http://dx.doi.org/10.1016/j.engfracmech.2006.01.023

Ferrari, V. J.; Hanai, J. B.; Souza, R. A. 2013. Flexural strengthening of reinforcement concrete beams using high performance fiber reinforcement cement-based composite (HPFRCC) and carbon fiber reinforced polymers (CFRP), Construction and Building Materials 48: 485-498. http://dx.doi.org/10.1016/j.conbuildmat.2013.07.026

Habel, K.; Denarié, E.; Brühwiler, E. 2007. Experimental investigation of composite ultra-high-performance fiberreinforced concrete and conventional concrete members, ACI Structural Journal 104(1): 93-101.

Haddad, R. H.; Shannag, J. M.; Al-Hambouth, M. T. 2008. Repair of reinforced concrete beams damaged by alkalisilica reaction, ACI Structural Journal 105(2): 145-153.

Hussein, M.; Kunieda, M.; Nakamura, H. 2012. Strength and ductility of RC beams strengthened with steel-reinforced strain hardening cementitious composites, Cement \& Concrete Composites 34(9): 1061-1066.

http://dx.doi.org/10.1016/j.cemconcomp.2012.06.004

Kaklauskas, G.; Ghaboussi, J. 2001. Stress-strain relations for cracked tensile concrete from RC beam tests, Journal of Structural Engineering 127(1): 64-73.

http://dx.doi.org/10.1061/(ASCE)0733-9445(2001)127:1(64)

Karihaloo, B. L. 2012. CARDIFRC - from concept to industrial application, High Performance Fiber Reinforced Cement Composites 6, Vol. 2 of the series RILEM State of the Art Reports. Springer, 397-404. http://dx.doi.org/10.1007/978-94-007-2436-5

Kim, D. J.; Wille, K.; Naaman, A. E.; El-Tawil, S. 2012. Strength dependent tensile behavior of strain hardening fiber reinforced concrete, High Performance Fiber Reinforced Cement Composites 6, Vol. 2 of the series RILEM State of the Art Reports. Springer, 3-10. http://dx.doi.org/10.1007/978-94-007-2436-5 1

Kim, Y. Y.; Lee, B. Y.; Bang, J. W.; Han, B. C.; Feo, L.; Cho, C. G. 2014. Flexural performance of reinforced concrete beams strengthened with strain-hardening cementitious composite and high strength reinforcing steel bar, Composites: Part B 56: 512-519.

http://dx.doi.org/10.1016/j.compositesb.2013.08.069

Kobayashi, K.; Rokugo, K. 2013. Mechanical performance of corroded RC member repaired by HPFRCC patching, Construction and Building Materials 39: 139-147. http://dx.doi.org/10.1016/j.conbuildmat.2012.05.013

Krstulovic-Opara, N.; Dogan, E.; Uang, C. M.; Haghayeghi, A. R. 1997. Flexural behavior of composite reinforced concrete slurry-infiltrated mat concrete (SIMCON) members, $A C I$ Structural Journal 94(5): 502-511.

Li, Q. H.; Xu, S. L. 2009. Experimental investigation and analysis on flexural performance of functionally graded composite beam crack-controlled by ultrahigh toughness cementitious composites, Science in China Series E: Technological Sciences 52(6): 1648-1664. http://dx.doi.org/10.1007/s11431-009-0161-x

Marčiukaitis, G.; Valivonis, J.; Bareišis, J. 2007. An analysis of the joint operation of a CFRP concrete in flexural elements, Mechanics of Composite Materials 43(5): 467478. http://dx.doi.org/10.1007/s11029-007-0044-9

Martinola, G.; Meda, A.; Plizzari, G. A.; Rinaldi, Z. 2010. Strengthening and repair of $\mathrm{RC}$ beams with fiber reinforced concrete, Cement \& Concrete Composites 32(9): 731-739. http://dx.doi.org/10.1016/j.cemconcomp.2010.07.001

Naaman, A. E.; Reinhardt, H. W. 2006. Proposed classification of HPFRCC composites based on their tensile response, Materials and Structures 39(5): 547-555. http://dx.doi.org/10.1617/s11527-006-9103-2

Nan, W.; Shi-lang, X. 2011. Flexural response of reinforced concrete beams strengthened with post-poured ultrahigh toughness cementitious composites layer, Journal of Central South University of Technology 18(3): 932-939. http://dx.doi.org/10.1007/s11771-011-0783-6

Noshiravani, T.; Brühwiler, E. 2010. Behaviour of UHPFRCC-RC composite beams subjected to combined bending and shear, in $8^{\text {th }}$ fib PhD Symposium in Kgs. Lyngby, Denmark, 20-23 June 2010, Denmark. 6 p.

Santos, P. M. D.; Júlio, E. N. B. S.; Silva, V. D. 2007. Correlation between concrete-to-concrete bond strength and the roughness of the substrate surface, Construction and Building Materials 21(8): 1688-1695. http://dx.doi.org/10.1016/j.conbuildmat.2006.05.044

Skuturna, T.; Valivonis, J.; Vainiūnas, P.; Marčiukaitis, G.; Daugevičius, M. 2008. Analysis of deflections of bridge girders strengthened by carbon fibre reinforcement, The Baltic Journal of Road and Bridge Engineering 3(3): 145151. http://dx.doi.org/10.3846/1822-427X.2008.3.145-151 
Skuturna, T.; Valivonis, J. 2014. Design method for calculating load-carrying capacity of reinforced concrete beams strengthened with external FRP, Construction and Building Materials 50: 577-583. http://dx.doi.org/10.1016/j.conbuildmat.2013.10.015

Skuturna, T.; Valivonis, J. 2015. The statistical evaluation of design methods of the load-carrying capacity of flexural reinforced concrete elements strengthened with FRP, Archives of Civil and Mechanical Engineering 15(1): 214222. http://dx.doi.org/10.1016/j.acme.2014.04.005

Wille, K.; El-Tawil, S.; Naaman, A. E. 2012. Strain rate dependent tensile behavior of ultra-high performance fiber reinforced concrete, High Performance Fiber Reinforced Cement Composites 6, Vol. 2 of the series RILEM State of the Art Reports. Springer, 381-387.

http://dx.doi.org/10.1007/978-94-007-2436-5 46
Yoo, D. Y.; Lee, J. H.; Yoon, Y. S. 2013. Effect of content on mechanical and fracture properties of ultra-high performance reinforced cementitious composites, Composite Structures 106: 742-753. http://dx.doi.org/10.1016/j.compstruct.2013.07.033

Zhang, D.; Ueda, T.; Furuuchi, H. 2012. Concrete cover separation failure of overlay-strengthened reinforced concrete beams, Construction and Building Materials 26(1): 735745. http://dx.doi.org/10.1016/j.conbuildmat.2011.06.082

Zofka, A.; Paliukaite, M.; Vaitkus, A.; Maliszewska, D.; Josen, R.; Bernier, A. 2014. Laboratory study on the influence of casting on properties of ultra-high performance fibre reinforced concrete (UHPFRC) specimens, Journal of Civil Engineering and Management 20(3): 380-388. http://dx.doi.org/10.3846/13923730.2014.913680

Mykolas DAUGEVIČIUS. Associate professor at the Department of Reinforced Concrete and Masonry Structures, Vilnius Gediminas Technical University. Research interests: the theory of reinforced concrete behaviour, composite materials and their calculation methods, rehabilitation of structures, thin walled structures.

Juozas VALIVONIS. Professor at the Department of Reinforced Concrete and Masonry Structures, Vilnius Gediminas Technical University. Research interests: the theory of reinforced concrete behaviour, composite materials and their calculation methods, reinforced concrete bridges.

Tomas SKUTURNA. Associate professor at the Department of Reinforced Concrete and Masonry Structures, Vilnius Gediminas Technical University. Research interests: the theory of reinforced concrete behaviour, composite structures and their calculation methods, rehabilitation of structure.

Vladimir POPOV. Associate professor at the Department of Reinforced Concrete and Masonry Structures, Vilnius Gediminas Technical University. Research interests: the theory of reinforced concrete behaviour, composite materials and their calculation methods, theory of masonry behaviour, finite element analysis, building information modeling. 